Article

\title{
Analysis of Lightning-Induced Voltages Effect with SPD Placement for Sustainable Operation in Hybrid Solar PV-Battery Energy Storage System
}

\author{
Nor Izzati Ahmad ${ }^{1, *(\mathbb{D})}$, Zaipatimah Ali ${ }^{1, *}$, Mohd Zainal Abidin Ab. Kadir ${ }^{1,2, * \mathbb{C}}$, Miszaina Osman ${ }^{1} \mathbb{D}$, \\ Nur Hazirah Zaini ${ }^{3}$ and Muhammad Hakirin Roslan ${ }^{4}$ \\ 1 Institute of Power Engineering (IPE), Putrajaya Campus, Universiti Tenaga Nasional, Jalan Ikram-UNITEN, \\ Kajang 43000, Malaysia; miszaina@uniten.edu.my \\ 2 Centre for Electromagnetic and Lightning Protection Research (CELP), Advanced Lightning, Power, and \\ Energy Research Centre (ALPER), Faculty of Engineering, Universiti Putra Malaysia, Serdang 43400, Malaysia \\ 3 Power, High Voltage, and Energy (PHIVE) Research Group, Faculty of Engineering and Built Environment, \\ Universiti Sains Islam Malaysia, Nilai 71800, Malaysia; nurhazirah@usim.edu.my \\ 4 Faculty of Engineering, Universiti Pertahanan Nasional Malaysia, Kem Sungai Besi, \\ Kuala Lumpur 57000, Malaysia; hakirin@upnm.edu.my \\ * Correspondence: nor.izzati@uniten.edu.my (N.I.A.); zaipatimah@uniten.edu.my (Z.A.); \\ mzk@upm.edu.my (M.Z.A.A.K.); Tel.: +60-13-465-2778 (N.I.A.)
}

\section{check for} updates

Citation: Ahmad, N.I.; Ali, Z.; Ab. Kadir, M.Z.A.; Osman, M.; Zaini, N.H.; Roslan, M.H. Analysis of Lightning-Induced Voltages Effect with SPD Placement for Sustainable Operation in Hybrid Solar PV-Battery Energy Storage System. Sustainability 2021, 13, 6889. https://doi.org/ $10.3390 /$ su13126889

Academic Editors: Marc A. Rosen and Samad M. E. Sepasgozar

Received: 26 April 2021

Accepted: 15 June 2021

Published: 18 June 2021

Publisher's Note: MDPI stays neutral with regard to jurisdictional claims in published maps and institutional affiliations.

Copyright: (c) 2021 by the authors. Licensee MDPI, Basel, Switzerland. This article is an open access article distributed under the terms and conditions of the Creative Commons Attribution (CC BY) license (https:// creativecommons.org/licenses/by/ $4.0 /)$.
Abstract: This paper discusses the lightning-induced voltage effect on a hybrid solar photovoltaic (PV)-battery energy storage system with the presence of surge protection devices (SPD). Solar PV functions by utilizing solar energy, in generating electricity, to supply to the customer. To ensure its consistency, battery energy storage is introduced to cater to the energy demand. For the countries located at the Equator, lightning has always become a major issue for the system to operate at maximum efficiency, due to its nature of installation in open space areas where the equipment may suffer serious damage that may stop the operation abruptly. To minimize the possible damages, insulation coordination on the lightning protection system is needed. Hence, three case studies, i.e., lightning current amplitude, lightning strike distance, and cable length are presented in this paper, which the quantified analysis is taking into account, to identify the performance of the system with the single installation of SPD Class II at DC and AC sides. The simulation results have contributed towards a better understanding of the importance of SPDs, and the need to properly coordinate according to the standard, taking into account the quantified information obtained from this work, hence providing the necessity of proper installation of SPD will provide better maintenance and prolong the lifespan of the equipment.

Keywords: hybrid solar PV; battery energy storage; lightning-induced voltage; insulation coordination; surge protection device; lightning strike distance; lightning current amplitude; cable length; quantify analysis; EMTP-RV

\section{Introduction}

Nowadays, the use of electrical power is a must, and basic need, which plays a vital role in the daily routine of all individuals all over the world. The global electrical energy demand keeps increasing due to the high populations in every country, including Malaysia. To fulfill the electrical energy demand, utility companies are working hard to generate non-renewable energy resources. However, it is not a sustainable option for the future due to the environmental pollution issue, and the depletion of resources [1]. Thus, it is crucial to mitigate the consumption of non-renewable energy and it is where renewable energy is required for future planning [2].

Today, amongst the available renewable energy resources, solar energy is the most reliable and actively used in the world. Solar energy provides a lot of advantages: clean 
energy, produce no noise, low maintenance cost, and have diverse applications [3]. Hence, to fully utilize it, solar photovoltaic has become one of the most desired technologies in the world, including in Malaysia. In Malaysia, the growth rate of solar photovoltaic (PV) installation has drastically increased since Malaysia enjoys sufficient solar radiation within the range of 4 to $8 \mathrm{~h}$ per day [4,5]. To make the electricity industry more effective and profitable, the Government has also implemented the tariff mechanisms under the 2011 Renewable Energy Act [6]. As reported in the Sustainable Energy Development Authority (SEDA) National Survey Report of PV Power Applications in Malaysia 2019 [7], Table 1 tabulates the annual total capacity of solar PV power from 2012 until 2019 provided by Sustainable Energy Development Authority (SEDA) Malaysia and Energy Commission (EC).

Table 1. Total Solar Photovoltaic (PV) Power Installed from 2012 until 2019 [7].

\begin{tabular}{ccccc}
\hline & & \multicolumn{2}{c}{ Grid-Connected (MW) } \\
\cline { 3 - 4 } Year & Off-Grid (MW) & $\begin{array}{c}\text { Decentralized } \\
\text { (Residential, Commercial } \\
\text { and Industrial) }\end{array}$ & $\begin{array}{c}\text { Centralized } \\
\text { (Ground-Mounted, Floating } \\
\text { and Agricultural) }\end{array}$ \\
\hline 2012 & 1.00 & 10.46 & 15.83 & Total (MW) \\
2013 & 1.00 & 56.47 & 59.00 & 116.47 \\
2014 & 1.00 & 90.75 & 79.00 & 170.75 \\
2015 & 1.00 & 139.36 & 80.67 & 221.03 \\
2016 & 1.00 & 197.98 & 86.92 & 285.90 \\
2017 & 8.90 & 230.19 & 38.92 & 328.01 \\
2018 & 35.64 & 302.68 & 715.42 & 737.74 \\
2019 & 41.53 & 371.12 & & 1128.25 \\
\hline
\end{tabular}

By implementing all the tariff mechanisms, renewable energy would become a good investment for a long-term period in industries, as well as individuals, due to its secure access to the grid and a reasonable price per unit [8]. In addition, solar energy also has become a key role in empowering smart cities. The smart city concept aims to adopt the Internet-of-Things (IoT) technologies, improve the living standards, and focus on sustainability of community living spaces, whereas utilities aim to provide sustainable and reliable renewable energy, which leads to economic growth $[9,10]$. Considering how advanced smart technologies are these days, the smart city and utilities also improve by having the sensors, utility's smart meter, video cameras, Wi-Fi, etc. Thus, it can help to serve smart city initiatives in secluded areas and provide a better solution for system management.

Besides that, solar energy has to be used in the right way, and the electrical energy produced from solar PV system is a commodity that may be wasted if it is not preserved or consumed properly. Since solar energy is weather dependent, which does not work consistently all the time and has unstable fluctuations due to the weather changes, and thus it is difficult to adjust the electrical energy to cater to the energy demand. Furthermore, the electrical energy demand is expected to increase in the next few years. Hence, it is necessary to consider a battery energy storage system in conjunction with a solar PV system. This might help the power utility to ensure the consistency of supplying electricity to the customer and to provide an effective solution to accommodate the potential high demand by downsizing the maximum demand tremendously [11]. Therefore, a battery energy storage system plays a key role in supporting the high demand from customers.

However, since the installation of solar PV systems are usually located and exposed on the rooftop or outside areas, the chances of such a system to be struck by lightning are very high, especially in areas that are prone to lightning. For many countries, especially those that are close to the Equator, lightning has always been a major threat to power systems, which can cause overvoltage due to direct lightning strikes and indirect lightning strikes. In this study, indirect lightning strikes are the prime interest, since they can cause significant problems to power systems, which usually strike the ground surface or a nearby object, 
while the lightning-induced overvoltage occurs due to electromagnetic coupling between the system and the lightning strike channel [12]. Figure 1 shows the types of lightning.

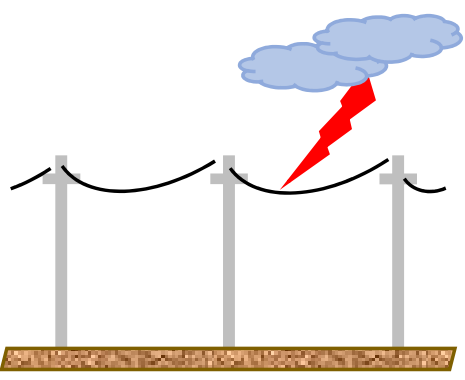

(a)

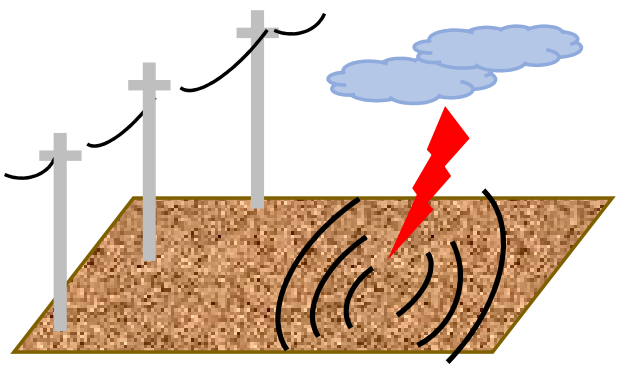

(b)

Figure 1. Types of lightning (a) Direct lightning strike (b) Indirect lightning strike.

Malaysia is one of the countries that have an isokeraunic level of about 200 thunderstorm days every year and is known as the 'Crown of Lightning' in the world $[13,14]$. Based on statistical data on the damage to solar PV systems in South Africa, about 31.2\% of the damage recorded whereby caused by lightning strikes [15]. Besides, Malaysia also has a high potential to receive the same experiences due to its location, which is near to the Equator. Malaysia is placed within the top five countries with a high occurrence of lightning activity [16,17]. It causes more than 100 deaths in Malaysia over 10 year periods and also encounters more than $70 \%$ of power outages due to lightning events [14]. As reported in [18-25], few studies have investigated either direct, or indirect, lightning strikes that contribute to the major damages of the solar PV systems. In Malaysia, there are a few solar PV systems available, such as the ones located at Puchong, Selangor, and Terengganu, etc., that have also experienced damages caused by lightning, although there is no official data recorded. SEDA also has received several complaints on damaged equipment and distribution boards of the solar PV system, especially the inverters.

The main reason such cases happen is due to the lack of knowledge and exposure to the need to carry out an insulation coordination study against lightning. Insulation coordination refers to the relationship between the insulation of the various equipment in a power system and the insulation of the surge protective devices (SPD) used to protect equipment from overvoltage [26]. The damages depend on a few critical factors based on lightning characteristics on the solar PV system i.e., lightning current amplitude, lightning striking distance, cable length, type's selection, and placement of SPD [27]. Hence, insulation coordination studies are required to protect the equipment of the system from the secondary effect of indirect lightning. To ensure all the equipment is properly protected by the SPD, the protective devices must be properly coordinated according to the desired guideline. Therefore, the objective of this paper is to study the effect of the lightning-induced voltage on hybrid solar PV-battery energy storage systems with the single installation of SPD Class II at DC and AC sides based on few case studies. Further investigation was made through sensitivity analysis to identify the performance of the system by varying several aspects of system design. The quantitative analyses carried out in this study are crucially needed for the performance evaluation of the overall system and equipment, taking into account the impulse withstand voltage, as referred in the standards of IEC TR 63227, MS IEC 60664-1 and PD CLC/TS 50539-12. Therefore, an appropriate protection scheme shall be assigned and coordinated accordingly.

\section{Insulation Coordination and Overvoltage Protection for Equipment in Hybrid Solar PV-Battery Energy Storage System}

During operation, the solar PV systems are highly exposed to various environmental factors and potential interference like lightning events. The damage to solar PV modules, 
inverter, battery energy storage, charge controllers, data monitoring, and communication systems can result from direct, or indirect, lightning strikes. Furthermore, unsupervised system installation may result in damage after a short time, and system failure or downtimes result in high repair and replacement costs as well as loss of productivity. Thus, these issues can be mitigated by carrying out insulation coordination studies, specifically on lightning protection systems, since the lightning-induced voltage is one of the factors that can cause overvoltage to the system. A few factors must be considered in insulation coordination studies, such as the lightning protection level, the surge protective devices' placement, and numbers, as well as rating, and the connection or bonding between the panels. Figure 2 illustrates the classification lightning protection system (LPS) for a hybrid solar PV-battery energy storage system.

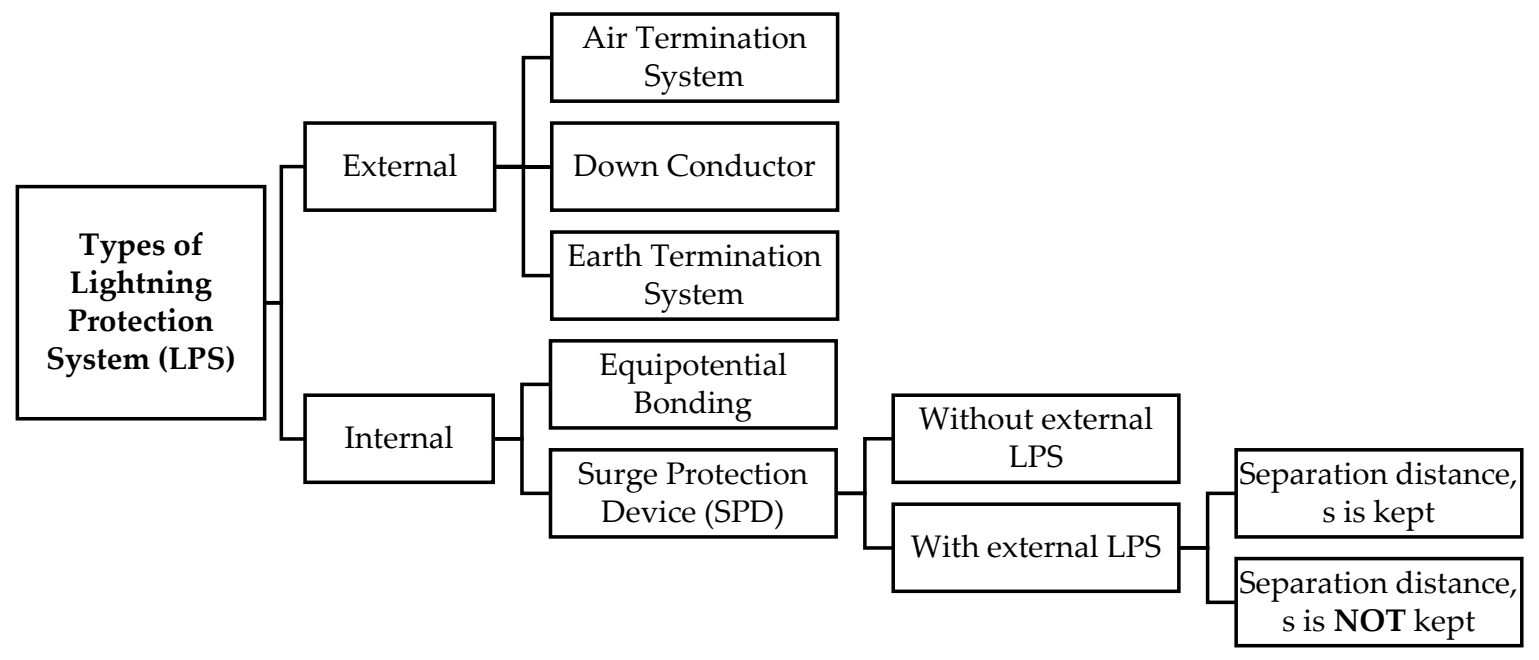

Figure 2. Classification of Lightning Protection System (LPS) [28,29].

There are several standards and guidelines available for the solar PV system that govern the aspects of lightning protection system (LPS) installation for building and solar PV systems, which can be obtained from the International Electrotechnical Committee (IEC), Malaysian Standard (MS), and various recognized bodies such as MS IEC 60664-1, MS IEC 62109-1, PD CLC/TS 50539-12 and IEC TR 63227, BS IEC 61643-11 and BS IEC 6164331 , which can be referred for solar PV system installation and insulation coordination for equipment within low voltage systems [30-35]. The damage that occurred to the equipment on the hybrid solar PV-battery energy storage system can also be determined by referring to the overvoltage category as tabulated in Table 2.

Table 2. Category of overvoltages [30,32].

\begin{tabular}{ccc}
\hline Category & Description & Examples \\
\hline I & $\begin{array}{c}\text { Applies to equipment connected to a circuit } \\
\text { where transient voltages have been reduced to } \\
\text { a low level. }\end{array}$ & $\begin{array}{c}\text { Equipment that containing electronic } \\
\text { circuits protected to this level. }\end{array}$ \\
II & $\begin{array}{c}\text { Applies to non-permanently connected } \\
\text { equipment, including energy-consuming } \\
\text { equipment supplied by the fixed installation. }\end{array}$ & $\begin{array}{c}\text { Appliances, portable tools, and } \\
\text { plug-connected equipment. }\end{array}$ \\
III & $\begin{array}{c}\text { Applies to fixed installations equipment } \\
\text { including the main distribution board. }\end{array}$ & $\begin{array}{c}\text { Switchgear and equipment in an } \\
\text { industrial installation. }\end{array}$ \\
\hline IV & $\begin{array}{c}\text { Applies to permanently connected equipment } \\
\text { at the origin of the installation. }\end{array}$ & $\begin{array}{c}\text { Meters, primary overcurrent protection } \\
\text { equipment, and equipment directly } \\
\text { connected to outdoor open lines. }\end{array}$ \\
\hline
\end{tabular}


Table 3 defines the values of impulse withstand voltage and the temporary overvoltage for low voltage circuits which are adopted from the standard of MS IEC 60664-1 and MS IEC 62109-1.

Table 3. Insulation voltage for low voltage circuits [30,32].

\begin{tabular}{|c|c|c|c|c|c|}
\hline Column 1 & 2 & 3 & 4 & 5 & 6 \\
\hline \multirow{3}{*}{$\begin{array}{c}\text { System Voltage (V) } \\
(\text { (7.3.7.2) }\end{array}$} & \multicolumn{4}{|c|}{ Impulse Withstand Voltage (V) } & \multirow{3}{*}{$\begin{array}{c}\text { Main Circuits } \\
\text { Temporary Overvoltage } \\
\text { (peak/rms) } \\
\text { (See NOTE 5) }\end{array}$} \\
\hline & \multicolumn{4}{|c|}{ Overvoltage Category } & \\
\hline & $\mathbf{I}$ & II & III & IV & \\
\hline $50 \mathrm{~V}_{\mathrm{rms}}$ or $71 \mathrm{~V}_{\mathrm{dc}}$ & 330 & 500 & 800 & 1500 & $1770 / 1250$ \\
\hline $100 \mathrm{~V}_{\mathrm{rms}}$ or $141 \mathrm{~V}_{\mathrm{dc}}$ & 500 & 800 & 1500 & 2500 & $1840 / 1300$ \\
\hline $150 \mathrm{~V}_{\mathrm{rms}}$ or $213 \mathrm{~V}_{\mathrm{dc}}$ & 800 & 1500 & 2500 & 4000 & $1910 / 1350$ \\
\hline $300 \mathrm{~V}_{\mathrm{rms}}$ or $424 \mathrm{~V}_{\mathrm{dc}}$ & 1500 & 2500 & 4000 & 6000 & $2120 / 1500$ \\
\hline $600 \mathrm{~V}_{\mathrm{rms}}$ or $849 \mathrm{~V}_{\mathrm{dc}}$ & 2500 & 4000 & 6000 & 8000 & $2550 / 1800$ \\
\hline $1000 \mathrm{~V}_{\mathrm{rms}}$ or $1500 \mathrm{~V}_{\mathrm{dc}}$ & 4000 & 6000 & 8000 & 12,000 & $3110 / 2200$ \\
\hline
\end{tabular}

NOTE 1 Interpolation is not permitted in main circuits but is permitted in other circuits.

NOTE 2 The last rows only apply to single-phase systems, or to the phase-to-phase voltage in three-phase systems

NOTE 3 Column 6, temporary overvoltage, only applies to main circuits.

NOTE 4 PV circuits are in general OVCII with a minimum impulse voltage of $2500 \mathrm{~V}$-see 7.3.7.1.2b.

NOTE 5 Three values are derived using the formula (1200 V + system voltage) from IEC 60664-1.

Description: $\mathrm{V}_{\mathrm{rms}}=$ root-mean-square voltage, $\mathrm{V}_{\mathrm{dc}}=$ direct current voltage, $\mathrm{OVCII}=$ Overvoltage category II.

The overvoltage in hybrid solar PV-battery energy storage system can be found in few conditions; (a) caused by the direct strike to the external lightning protection system (LPS) or lightning flashes nearby the solar PV installations, (b) caused by lightning-induced currents distributed into the electrical network, (c) transmitted from the distribution network due to switching [31]. Therefore, to ensure adequate protection of the equipment, the protection voltage shall be lower than the impulse withstand voltage of the equipment to be protected [31]. In between the impulse withstand voltage of the equipment and protection voltage, at least $20 \%$ of the safety margin should be kept (CLC/TS 61643-12) [31]. Table 4 presents the impulse withstand voltage for equipment between solar PV and inverters at the DC side, which is adopted from standard PD CLC/TS 50539-12.

Table 4. Impulse withstand voltage for equipment between PV and inverter [31].

\begin{tabular}{|c|c|c|c|}
\hline \multirow{2}{*}{$\begin{array}{l}\text { Maximum Open Circuit } \\
\text { Voltage, } V_{\text {oc } \max }(\mathrm{V})\end{array}$} & \multicolumn{3}{|c|}{ Impulse Withstand Voltage (V) } \\
\hline & PV Generator ${ }^{a}$ & Inverter $^{b}$ & Other Equipment $^{c}$ \\
\hline 100 & 800 & \multirow{4}{*}{$\begin{array}{c}2500 \\
\text { (minimum requirement) }\end{array}$} & 800 \\
\hline 150 & 1500 & & 1500 \\
\hline 300 & 2500 & & 2500 \\
\hline 424 & 4000 & & 4000 \\
\hline 600 & 4000 & \multirow{3}{*}{4000} & 4000 \\
\hline 800 & 5000 & & 5000 \\
\hline 849 & 6000 & & 6000 \\
\hline 1000 & 6000 & 6000 & 6000 \\
\hline 1500 & 8000 & 8000 & 8000 \\
\hline
\end{tabular}

${ }^{\mathrm{a}}$ Component withstand values are based on the basic insulation values according to standard IEC 61730-2 edition 2.0 [36]. ${ }^{\mathrm{b}}$ Component withstand values are based on EN 62109-1:2010, 7.3.7.1.2b. ${ }^{c}$ Component withstand values are based on impulse voltage, $\mathrm{U}_{\text {imp }}$ according to EN 60664-1:2007 overvoltage category II. 
As stated in MS IEC 62109-1 [32], the equipment of hybrid solar PV-battery energy storage system at DC side such as solar PV, the battery and inverter are assumed to be in overvoltage category II, whilst the inverter and transformer at the AC side are assumed to be overvoltage category III [37]. Therefore, the impulse withstand voltage for solar $\mathrm{PV}$, battery, and inverter on the DC side is $6 \mathrm{kV}$, while the inverter and low voltage (LV) transformer on the $\mathrm{AC}$ side are $2.5 \mathrm{kV}$ and $4 \mathrm{kV}$, respectively.

\section{Simulation Modelling in Electro-Magnetic Transient Program-Restructured Version (EMTP-RV) Software}

In this study, the EMTP-RV software is the most recent version of EMTP software, has been used to study the lightning-induced effect with surge protection device (SPD) placement in the hybrid solar PV-battery energy storage system. This section discusses the method of modelling the hybrid solar PV-battery energy storage system, lightning-induced voltage, and surge protection device (SPD) Class II.

The hybrid solar PV-battery energy storage system was made up of a 1-Megawatt (MW) solar PV system with an ideal battery energy storage system to produce DC power. Then, the DC power, converted through the inverter, passes the AC power through a $433 \mathrm{~V} / 11 \mathrm{kV}$ transformer to the utility grid. In order to simulate the effect of the indirect lightning strike on the system, two models were practiced; the Heidler model was used to simulate the lightning return stroke current, and the Rusck model was used to obtain the lightning-induced voltage. Lastly, the SPD Class II also was modelled to investigate the system's performance with a single installation of SPD in the system after being struck by indirect lightning. Throughout this simulation of modelling, the sensitivity analysis was made to identify the performance of the system with a single installation of SPD and without SPD.

\subsection{Modelling of Hybrid Solar PV-Battery Energy Storage System}

In this study, the $1 \mathrm{MW}$ solar PV system, was modeled based on the existing application in Puchong, Malaysia with the ideal battery energy storage system. It consists of solar PV arrays, inverters, ideal battery energy storage, transformer, and grid. The battery energy storage system was modelled based on the ideal properties provided in the master library of EMTP-RV software. The battery energy storage system was also assumed to be in full charge capacity when performing the sensitivity analysis on the effect of lightning-induced voltage with, and without, a single installation of SPD Class II in the hybrid solar PV-battery energy storage system. The hybrid solar PV-battery energy storage system converted from 715.2 $\mathrm{V}_{\mathrm{DC}}$ to $354.7 \mathrm{~V}_{\mathrm{AC}}$ output and supply to the grid through a transformer with a rating of 1.5 MVA $433 \mathrm{~V} / 11 \mathrm{kV}$. The irradiation and temperature of the solar PV were set according to the standard test condition (STC), which is $1000 \mathrm{~W} / \mathrm{m}^{2}$ and $25^{\circ} \mathrm{C}$, respectively. The detail of components of a hybrid solar PV-battery energy storage system is tabulated in Table 5.

Table 5. Detail of Equipment in a Hybrid Solar PV-Battery Energy Storage System.

\begin{tabular}{|c|c|c|}
\hline Equipment & \multicolumn{2}{|c|}{ Specifications } \\
\hline \multirow{3}{*}{ Solar PV } & Power & $1 \mathrm{MW}$ \\
\hline & Voltage & $715.2 \mathrm{~V}$ \\
\hline & Current & $1398.2 \mathrm{~A}$ \\
\hline Battery Energy Storage & Battery nominal capacity & $5.26 \mathrm{MWh}$ \\
\hline Inverter & $\begin{array}{c}\text { Nominal AC } \\
\text { Power per inverter }\end{array}$ & $20 \mathrm{~kW}$ \\
\hline \multirow[b]{2}{*}{ Transformer } & Rating & $1.5 \mathrm{MVA}$ \\
\hline & Type & $\begin{array}{l}\text { Step-up transformer } \\
\quad(433 \mathrm{~V} / 11 \mathrm{kV})\end{array}$ \\
\hline Grid & \multicolumn{2}{|c|}{$11 \mathrm{kV}$} \\
\hline
\end{tabular}




\subsection{Modelling of Lightning Return Stroke Current and Lightning-Induced Voltage}

Indirect lightning is termed when the lightning strikes a nearby object or the ground surface and causes the lightning-induced voltage, due to electromagnetic coupling between the lightning strike channel and the system [12]. The evaluation of lightninginduced voltage can be performed by using these two steps [38,39] as explained in Sections 3.2.1 and 3.2.2, respectively.

It is also worth noting that, the challenge of this study was to replicate the real lightning return stroke current and lightning-induced voltage by using the mathematical equation. Due to this, the Heidler and Rusck models were used as alternative equations to represent the lightning return stroke current and lightning-induced voltage. The simulated lightning-induced voltage was injected away from the hybrid solar PV-battery energy storage system. The injected point was assumed to be at the nearest point to the system, denoted as $x$ equals to 0 , with the lightning strike distances, $d$ was varied. However, there are some limitations in modelling the lightning whereby the application of the Rusck model is only considered perfect ground conductivity and the perpendicular lightning channel to the ground in other works related to induced effect $[38,40]$.

\subsubsection{Modelling of Lightning Return Stroke Current}

The Heidler function was modeled to illustrate the lightning current waveshapes. As recommended in standard IEC 62305-1 [41], the Heidler function produces more realistic results and starts with steepness 0 at $t$ equals 0 [42]. The lightning return stroke current was simulated by using a lightning waveshape of $8 / 20 \mu \mathrm{s}$, and was chosen to determine the lightning-induced effect, when the surge protection device (SPD) was connected to the system $[28,43,44]$. Nine lightning current amplitudes, ranging from $2 \mathrm{kA}$ to $200 \mathrm{kA}$, were selected, as referred to in the International Council on Large Electric Systems (CIGRE) distribution [45]. These values were also based on a statistical analysis of lightning activity at the Solar PV farm, Puchong in Selangor [28]. Therefore, the lightning waveshape was modelled by using the Heidler equation as expressed in Equation (1).

$$
i(t)=\frac{I_{m}}{\eta} \frac{\left(\frac{t}{\tau_{1}}\right)^{n}}{1+\left(\frac{t}{\tau_{1}}\right)^{n}} \exp ^{\left(-\frac{t}{\tau_{2}}\right)}
$$

where $I_{m}$ is the lightning peak current, $\eta$ is the correction factor of peak current, $\tau_{1}$ is the rise time constant, $\tau_{2}$ is the fall time constant, and $\mathrm{n}$ is the steepness factor. The parameters used to model the lightning waveshape of $8 / 20 \mu \mathrm{s}$ and its graph is shown in Table 6 and Figure 3, respectively.

Table 6. Parameters to model the lightning waveshape by using Heidler equation [41].

\begin{tabular}{cc}
\hline Parameters & Value \\
\hline Lightning waveshape & $8 / 20 \mu \mathrm{s}$ \\
Rise time, $\tau_{1}(\mu \mathrm{s})$ & 4.4 \\
Fall time, $\tau_{2}(\mu \mathrm{s})$ & 14 \\
$\mathrm{n}$ & 3 \\
\hline
\end{tabular}




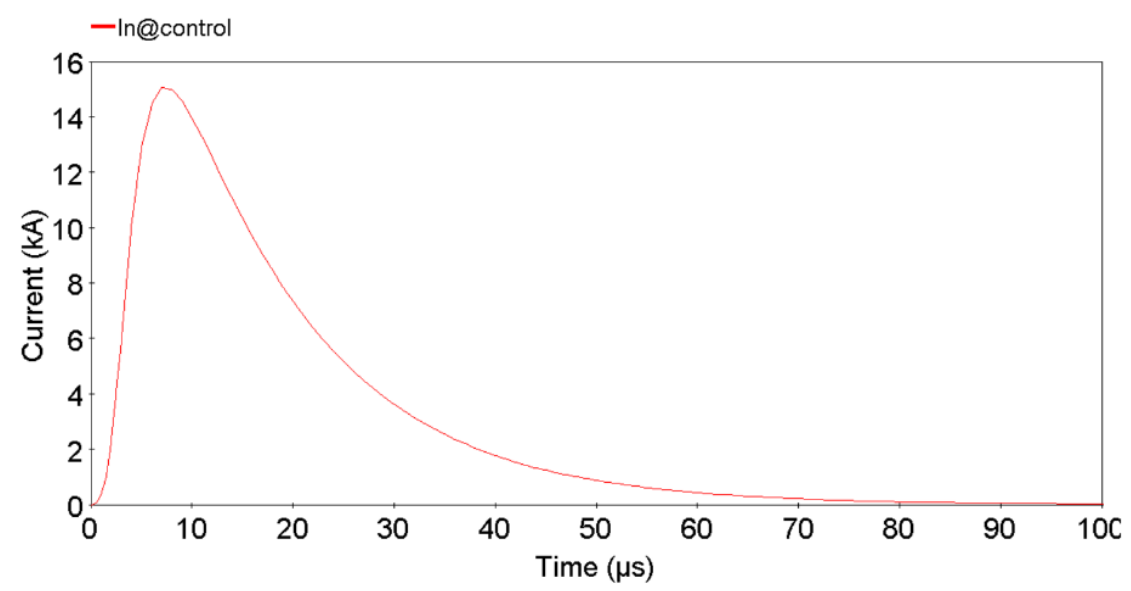

Figure 3. Lightning waveshape $8 / 20 \mu$ s.

\subsubsection{Modelling of Lightning-Induced Voltage}

There are three basic coupling models that were used to determine the lightninginduced voltage on a hybrid solar PV-battery energy storage system caused by an indirect lightning strike; i.e., Model of Rusck, Chowdhuri and Gross, and Agrawal et al. [46]. In this study, the Rusck model was chosen as a coupling model due to its simplification and mathematically correct which leads to consistent results [47,48]. The Rusck model was simulated using mathematical formula as expressed in Equation (2).

$$
v(x, t)=\frac{\zeta_{0} I_{0} h}{4 \pi} \beta\left(\frac{c t-x}{d^{2}+\beta^{2}(c t-x)^{2}}\left(1+\frac{x+\beta^{2}(c t-x)}{\sqrt{(\beta c t)^{2}+\frac{x^{2}+d^{2}}{\gamma^{2}}}}\right) \frac{c t+x}{d^{2}+\beta^{2}(c t+x)^{2}}\left(1+\frac{x+\beta^{2}(c t+x)}{\sqrt{(\beta c t)^{2}+\frac{x^{2}+d^{2}}{\gamma^{2}}}}\right)\right)
$$

where, $\beta=v / c$ is the ratio between the return stroke velocity and the light speed, $\zeta_{0}$ is $376.730313 \Omega$ (free space characteristics impedance), $I_{0}$ is the return stroke current, $d$ is the horizontal distance between the lightning channel and the system, $x$ is the point nearest to the lightning stroke, $h$ is the system height, and $\gamma$ is equal to $1 / \sqrt{ }\left(1-\beta^{2}\right)$.

\subsection{Modelling of Surge Protective Device (SPD)}

A surge protective device is a device that protects the equipment in the power system against surge voltages. It consists of at least one nonlinear component to limit the surge voltages and diverts the surge voltages to a distant ground in terms of amplitude [47]. The SPD is also one of the types of lightning protection systems applied in the hybrid solar PV-battery energy storage system. There are three classes of SPD, which are Class I, Class II, and Class III defined by their requirements for testing. With the typical Lightning Protection Level (LPL) of III and IV considered for solar PV farms, generally, the SPD class II is chosen for all low voltage electrical installations that must be able to discharge the lightning-induced voltage occurs from indirect lighting strike [49]. To prevent the induced effect from spreading in the power system, and also to protect the loads, this SPD is installed in a sub-distribution board [28].

Therefore, amongst the discharge technology available, varistor technology is designed with fast response behavior that fits the SPD testing. A varistor is also known as a variable resistor or metal oxide varistor (MOV) made from metal oxide ceramics, which is composed of zinc oxide $(\mathrm{ZnO})$ that has nonlinear resistance characteristics $[28,50]$, as shown in Figure 4. In this work, the SPD was modelled based on the MOV component in U-configuration, adopted from Section 9.2.2.6 of the standard PD CLC/TS 50539-12 [31]. This is due to the safety purposes whereby the flow of current can pass through the second varistor without being interrupted when one varistor fails [49]. 


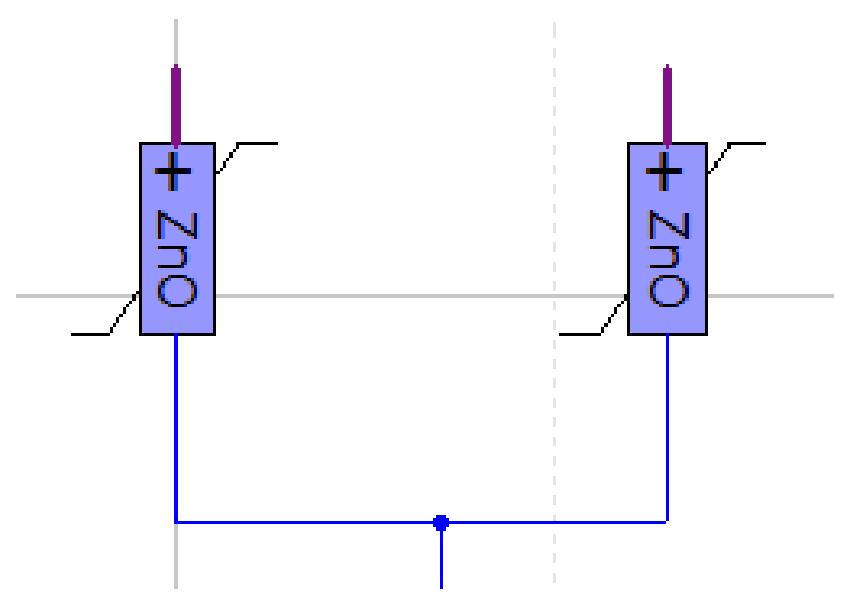

Figure 4. Surge arrestor in Electro-magnetic Transient Program-Restructured Version (EMTP-RV) software.

However, there is still a limitation in modelling the SPD whereby the installation of SPD in the hybrid solar PV-battery energy storage system was considered without an external lightning protection system (LPS). The SPD Class II also was modelled based on the manufacturer's datasheet to ensure its performance while testing with the simulation of lightning-induced voltage. Tables 7 and 8 tabulate the main characteristics for DC and AC SPD Class II and the current-voltage characteristics, respectively.

Table 7. Main characteristics for DC and AC SPD Class II [51,52].

\begin{tabular}{ccc}
\hline Key Characteristics & \multicolumn{2}{c}{ Value } \\
\cline { 2 - 3 } & DC SPD Class II & AC SPD Class II \\
\hline Maximum Discharge Current, $I_{\max }(\mathrm{kA})$ & 40 & 40 \\
Maximum Continuous Voltage, $U_{c}(\mathrm{kV})$ & 1.17 & 0.275 \\
Voltage Protection Level, $U_{p}(\mathrm{kV})$ & $\leq 1.9$ & $\leq 1.5$ \\
Nominal Discharge Current, $I_{n}(8 / 20 \mu \mathrm{s})(\mathrm{kA})$ & 15 & 20 \\
\hline
\end{tabular}

Table 8. Current-Voltage Characteristics for DC and AC SPD Class II [51,52].

\begin{tabular}{ccccccccccccc}
\hline & Current (kA) & 0.01 & 0.10 & 1 & 5 & 10 & 15 & 20 & 25 & 30 & 35 & 40 \\
\cline { 2 - 10 } $\begin{array}{c}\text { DC SPD } \\
\text { Class II }\end{array}$ & $\begin{array}{c}\text { Residual } \\
\text { Voltage, } \boldsymbol{U}_{\text {res }} \\
\mathbf{( k V )}\end{array}$ & 1.10 & 1.20 & 1.30 & 1.50 & 1.70 & 1.85 & 2.00 & 2.15 & 2.30 & 2.40 & 2.50 \\
\hline & $\begin{array}{c}\text { Current (kA) } \\
\text { AC SPD } \\
\text { Class II }\end{array}$ & 0.01 & 0.1 & 1 & 2 & 3 & 4 & 5 & 10 & 15 & 20 & 30 \\
\hline $\begin{array}{c}\text { Residual } \\
\text { Voltage, } \boldsymbol{U}_{\text {res }} \\
(\mathbf{k V )}\end{array}$ & 0.94 & 0.97 & 1.00 & 1.03 & 1.06 & 1.10 & 1.20 & 1.30 & 1.40 & 1.50 & 1.70 \\
\hline
\end{tabular}

Based on the abovementioned parameters, both DC and AC SPD Class II were tested with lightning waveshape $8 / 20 \mu$ s and nominal discharge current, $I_{n}$ under the Class II test as recommended in the standard BS EN 61643-31 [35]. The nominal discharge current is defined as the crest value of the current passing through the SPD with an $8 / 20 \mu$ s lightning current waveshape. Referring to the manufacturer's datasheet of DC and AC SPD Class II [51,52], Figures 5 and 6 successfully show the nominal discharge current of $15 \mathrm{kA}$ and $20 \mathrm{kA}$, based on $8 / 20 \mu$ s waveshape and their corresponding discharge voltage of $1.85 \mathrm{kV}$ and $1.50 \mathrm{kV}$, after testing with nominal discharge current, respectively. 


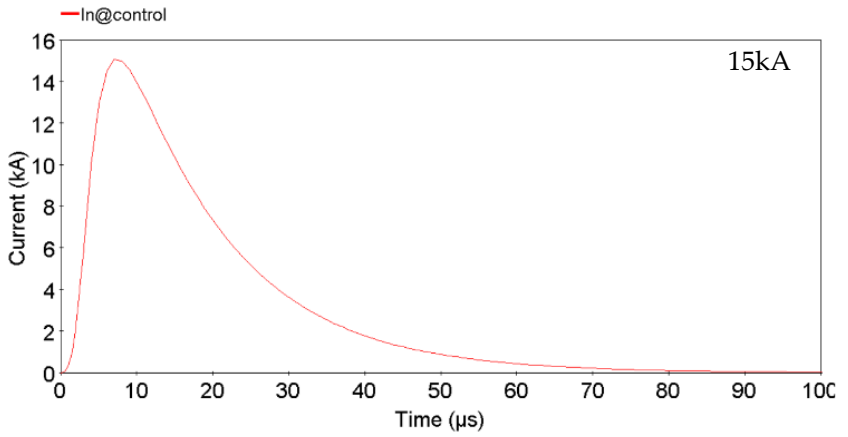

(a)

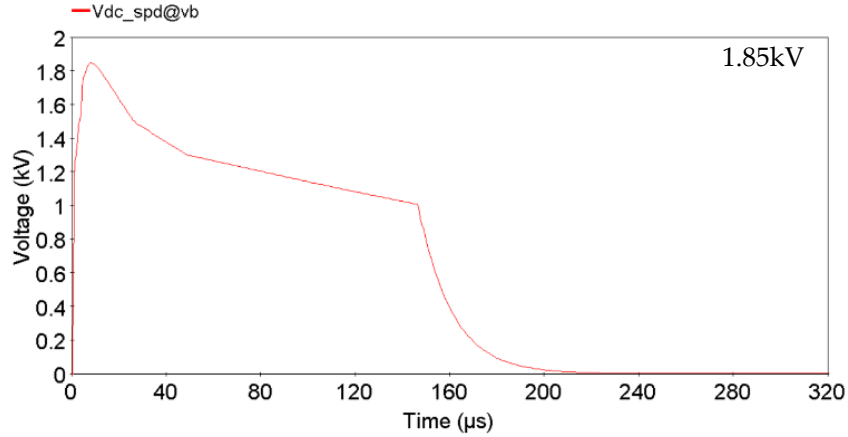

(b)

Figure 5. DC SPD Class II (a) Nominal discharge current of lightning waveshape $8 / 20 \mu$ s at $I_{n}=15 \mathrm{kA}$, (b) Discharge voltage after testing with $I_{n}$.

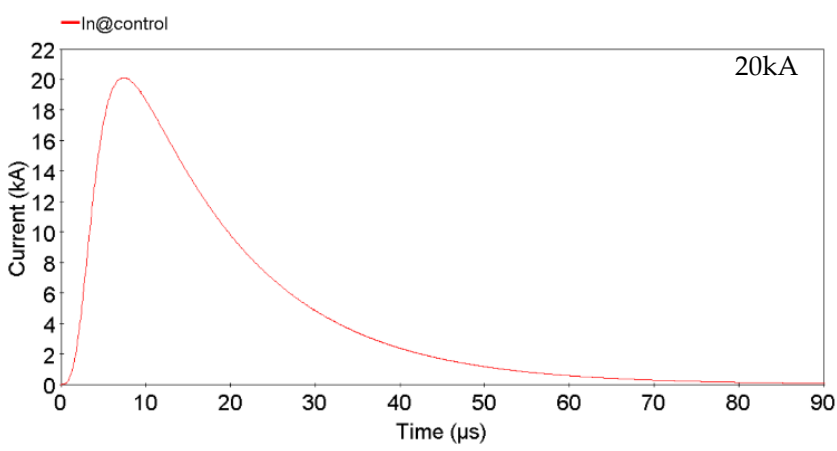

(a)

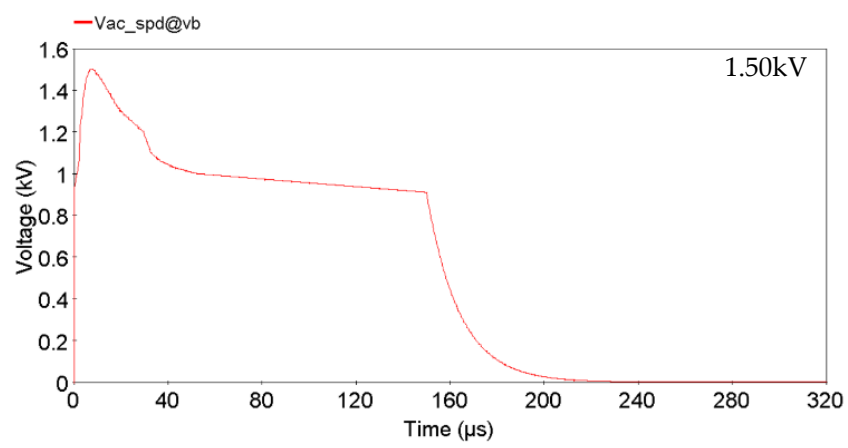

(b)

Figure 6. AC SPD Class II (a) Nominal discharge current of lightning waveshape $8 / 20 \mu$ s at $I_{n}=20 \mathrm{kA}$, (b) Discharge voltage after testing with $I_{n}$.

\section{Case Studies}

4.1. Placement of Surge Protection Device (SPD) on DC and AC Sides of Hybrid Solar PV-Battery Energy Storage System

In the placement of SPD, two types of SPD Class II were used, which are DC SPD Class II and AC SPD Class II. Each type of SPDs was placed near the DC inverter on the DC side and near the transformer on the AC side, respectively as shown in Figure 7. The placement of SPD Class II was based on standard IEC TR 63227, BS EN 61643-11, and BS EN 61643-31 standard [33-35]. The SPD's installation on a hybrid solar PV-battery energy storage system is required to protect the power supply as well as the system's communication circuits.

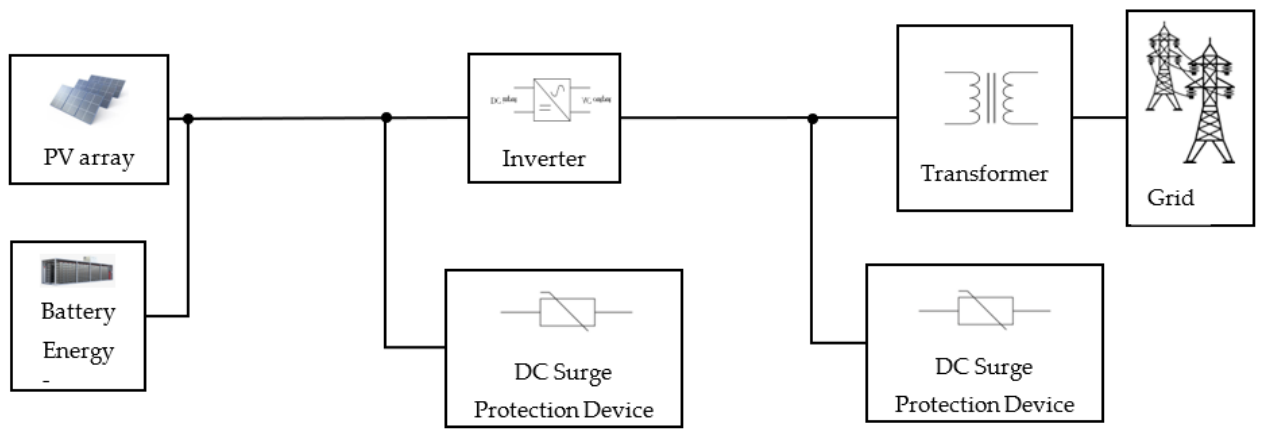

Figure 7. Placement of SPD Class II near the inverter on DC side and near the transformer on AC side. 


\subsection{Location of Lightning-Induced Voltage on Hybrid Solar PV-Battery Energy Storage System}

The case study demonstrates the indirect lightning strike by injecting lightning current waveshape of $8 / 20 \mu$ s to the ground or nearby object/system. By conducting this simulation, it results in the production of lightning-induced voltage at both DC and AC sides of the system which might damage or breakdown the electrical network, equipment, or data/communication line in the system. Given that, it is where the lightning protection system (e.g., surge protection device) is needed to ensure the system's efficiency in generating and supplying the power output to the grid. Thus, to identify the effectiveness of SPD, there are three case studies considered, namely the effects of lightning strike distance, lightning current amplitude, and cable length. In this study, the lightning-induced voltage model and geometry case study were presented in Figure 8a,b, respectively.

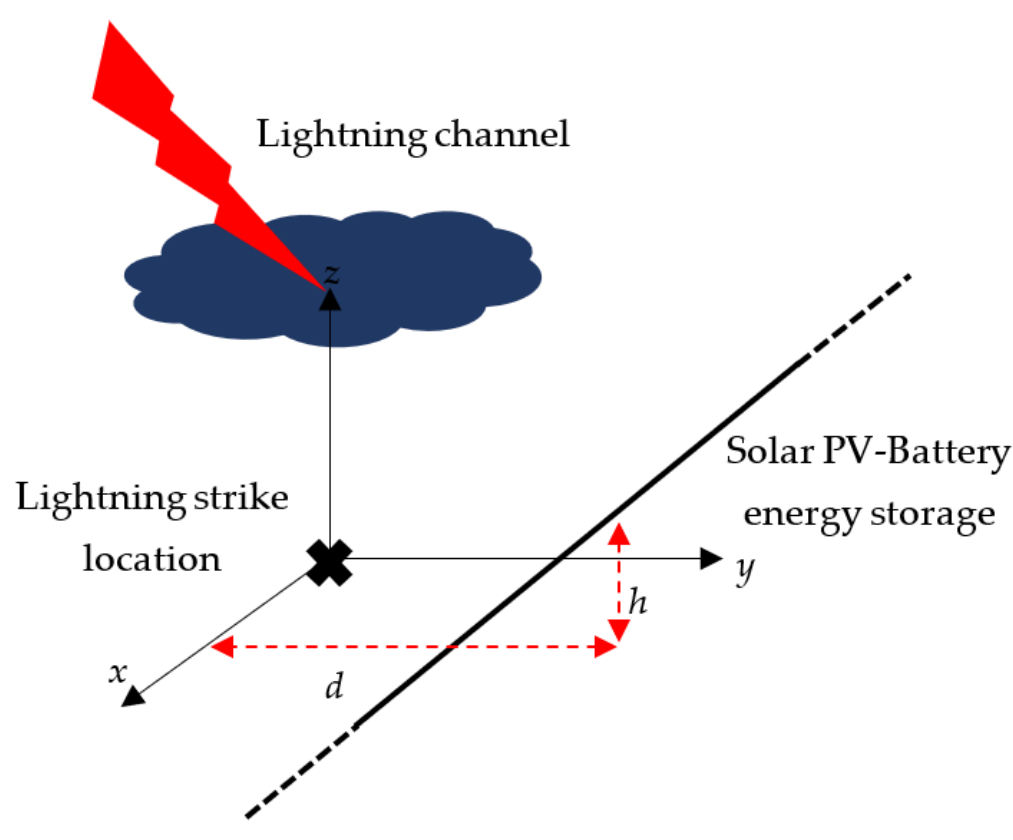

(a)

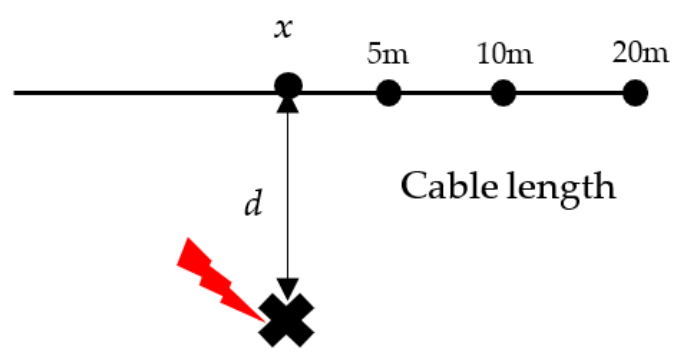

Lightning strike location

Figure 8. (a) Lightning-induced voltage model (b) Geometry adopted for the lightning-induced voltage.

Figures 9 and 10 illustrate the lightning waveshape of $8 / 20 \mu$ s struck at two locations; the DC and AC side of the system, respectively. To observe the effect of lightning-induced voltage, there are two measurement points denote as Point A (near the solar PV and battery) and Point B (near the DC inverter) on the DC side and another two measurement points denotes as Point C (near the AC inverter) and Point D (near the transformer) on the AC sides are considered as shown in Figures 9 and 10, respectively. 


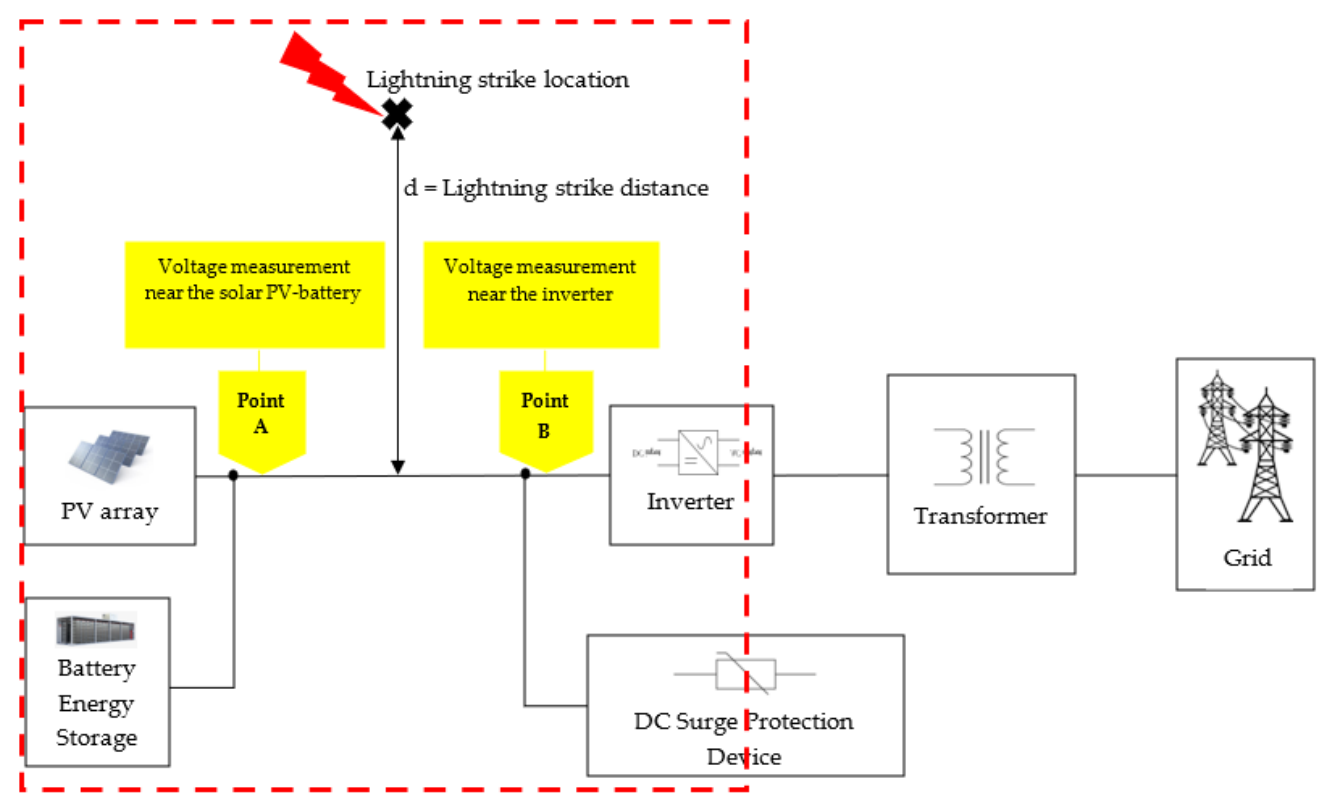

Figure 9. Illustration of lightning-induced voltage in the system when DC SPD Class II installed close to inverter on DC side. Point A (near the solar PV and battery; Point B (near the DC inverter).

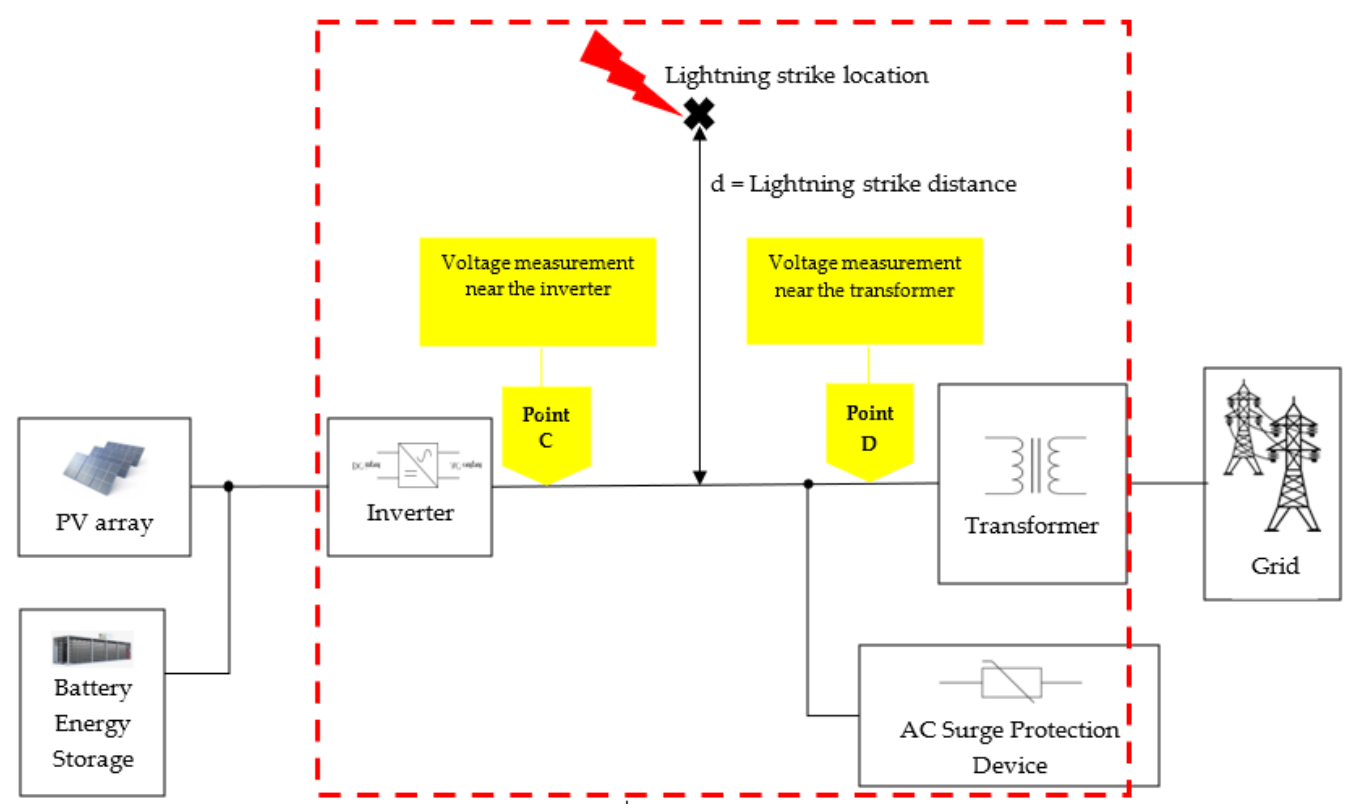

Figure 10. Illustration of lightning-induced in the system when AC SPD Class II installed close to transformer. Point C (near the AC inverter); Point D (near the transformer).

\section{Results and Discussion}

In this study, three case studies were carried out to simulate the effect of lightninginduced voltage analysis on a hybrid solar PV-battery energy storage system with the installation of SPD Class II on DC and AC sides. They are the lightning strike distances (i.e., $20 \mathrm{~m}, 50 \mathrm{~m}$, and $100 \mathrm{~m}$ ), the lightning current amplitudes, and the cable lengths (i.e., $5 \mathrm{~m}, 10 \mathrm{~m}$, and $20 \mathrm{~m}$ ). The parameters for simulation are tabulated in Table 9 and the measurement data of lightning-induced voltages are tabulated in Tables 10 and 11, respectively. Results in all case studies are compared with the ones without SPD [42] for quantifying analysis purposes. 
Table 9. List of parameters for simulation.

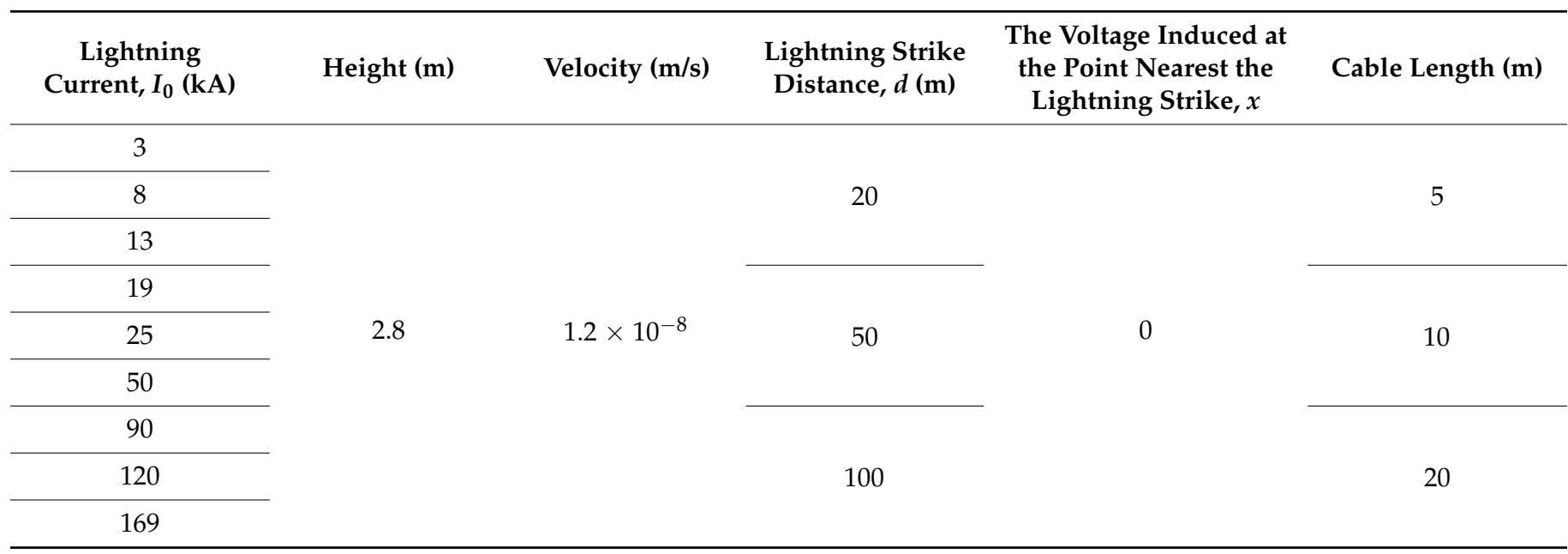

Table 10. Measurement of lightning-induced voltage on DC side.

\begin{tabular}{|c|c|c|c|c|c|c|c|c|}
\hline \multirow{4}{*}{$\begin{array}{c}\text { Lightning Current, } \\
I_{0}(\mathrm{kA})\end{array}$} & \multirow{4}{*}{$\begin{array}{l}\text { The Point Nearest the } \\
\text { Lightning Strike, } x\end{array}$} & \multirow{4}{*}{$\begin{array}{l}\text { Lightning Strike } \\
\text { Distance, } d(\mathrm{~m})\end{array}$} & \multicolumn{6}{|c|}{ Lightning-Induced Voltage (kV) } \\
\hline & & & \multicolumn{6}{|c|}{ DC SPD Class II } \\
\hline & & & \multicolumn{3}{|c|}{$\begin{array}{c}\text { Point A } \\
\text { (Near the Solar PV-Battery) }\end{array}$} & \multicolumn{3}{|c|}{$\begin{array}{c}\text { Point B } \\
\text { (Near the Inverter) }\end{array}$} \\
\hline & & & $5 \mathrm{~m}$ & $10 \mathrm{~m}$ & $20 \mathrm{~m}$ & $5 \mathrm{~m}$ & $10 \mathrm{~m}$ & $20 \mathrm{~m}$ \\
\hline \multirow{3}{*}{3} & & 20 & 1.01 & 1.03 & 1.13 & 1.01 & 1.01 & 1.03 \\
\hline & & 50 & 1.01 & 1.02 & 1.13 & 1.01 & 1.01 & 1.03 \\
\hline & & 100 & 0.98 & 1.00 & 1.11 & 0.98 & 0.98 & 1.02 \\
\hline \multirow{3}{*}{8} & & 20 & 2.26 & 2.26 & 2.42 & 1.35 & 1.29 & 1.26 \\
\hline & & 50 & 2.24 & 2.24 & 2.41 & 1.35 & 1.29 & 1.26 \\
\hline & & 100 & 2.20 & 2.20 & 2.37 & 1.34 & 1.29 & 1.26 \\
\hline \multirow{3}{*}{13} & & 20 & 3.40 & 3.42 & 3.65 & 1.47 & 1.39 & 1.31 \\
\hline & & 50 & 3.38 & 3.41 & 3.63 & 1.47 & 1.39 & 1.31 \\
\hline & & 100 & 3.31 & 3.34 & 3.57 & 1.46 & 1.38 & 1.30 \\
\hline \multirow{3}{*}{19} & & 20 & 4.77 & 4.81 & 5.07 & 1.61 & 1.46 & 1.38 \\
\hline & & 50 & 4.74 & 4.78 & 5.06 & 1.61 & 1.46 & 1.38 \\
\hline & & 100 & 4.64 & 4.68 & 4.96 & 1.60 & 1.46 & 1.37 \\
\hline \multirow{3}{*}{25} & & 20 & 6.14 & 6.18 & 6.48 & 1.73 & 1.53 & 1.43 \\
\hline & 0 & 50 & 6.10 & 6.14 & 6.46 & 1.73 & 1.53 & 1.43 \\
\hline & & 100 & 5.96 & 6.01 & 6.33 & 1.72 & 1.52 & 1.42 \\
\hline \multirow{3}{*}{50} & & 20 & 11.84 & 11.81 & 12.26 & 2.18 & 1.81 & 1.59 \\
\hline & & 50 & 11.76 & 11.76 & 12.23 & 2.18 & 1.80 & 1.59 \\
\hline & & 100 & 11.48 & 11.49 & 11.98 & 2.16 & 1.79 & 1.59 \\
\hline \multirow{3}{*}{90} & & 20 & 20.94 & 20.84 & 21.44 & 2.71 & 2.20 & 1.81 \\
\hline & & 50 & 20.80 & 20.71 & 21.39 & 2.66 & 2.19 & 1.81 \\
\hline & & 100 & 20.29 & 20.24 & 20.94 & 2.68 & 2.18 & 1.80 \\
\hline \multirow{3}{*}{120} & & 20 & 27.75 & 27.65 & 28.28 & 2.99 & 2.43 & 1.97 \\
\hline & & 50 & 27.56 & 27.42 & 28.24 & 2.99 & 2.42 & 2.00 \\
\hline & & 100 & 26.91 & 26.80 & 27.65 & 2.96 & 2.40 & 1.95 \\
\hline \multirow{3}{*}{169} & & 20 & 38.91 & 38.75 & 39.50 & 3.37 & 2.73 & 2.21 \\
\hline & & 50 & 38.63 & 38.43 & 39.44 & 3.36 & 2.72 & 2.21 \\
\hline & & 100 & 37.68 & 37.51 & 38.60 & 3.33 & 2.70 & 2.19 \\
\hline
\end{tabular}


Table 11. Measurement of lightning-induced voltage on AC side.

\begin{tabular}{|c|c|c|c|c|c|c|c|c|}
\hline \multirow{4}{*}{$\begin{array}{c}\text { Lightning } \\
\text { Current, } I_{0}(\mathrm{kA})\end{array}$} & \multirow{4}{*}{$\begin{array}{c}\text { The Point Nearest } \\
\text { the Lightning } \\
\text { Strike, } x\end{array}$} & \multirow{4}{*}{$\begin{array}{l}\text { Lightning Strike } \\
\text { Distance, } d(\mathrm{~m})\end{array}$} & \multicolumn{6}{|c|}{ Lightning-Induced Voltage $(\mathrm{kV})$} \\
\hline & & & \multicolumn{6}{|c|}{ AC SPD Class II } \\
\hline & & & \multicolumn{3}{|c|}{$\begin{array}{c}\text { Point C } \\
\text { (Near the Inverter) }\end{array}$} & \multicolumn{3}{|c|}{$\begin{array}{c}\text { Point D } \\
\text { (Near the Transformer) }\end{array}$} \\
\hline & & & $5 \mathrm{~m}$ & $10 \mathrm{~m}$ & $20 \mathrm{~m}$ & $5 \mathrm{~m}$ & $10 \mathrm{~m}$ & $20 \mathrm{~m}$ \\
\hline \multirow{3}{*}{3} & & 20 & 1.08 & 1.05 & 1.14 & 0.95 & 0.95 & 0.93 \\
\hline & & 50 & 1.07 & 1.04 & 1.13 & 0.95 & 0.94 & 0.93 \\
\hline & & 100 & 1.04 & 1.02 & 1.10 & 0.94 & 0.94 & 0.93 \\
\hline \multirow{3}{*}{8} & & 20 & 2.90 & 2.84 & 3.15 & 1.03 & 1.00 & 0.99 \\
\hline & & 50 & 2.87 & 2.81 & 3.13 & 1.03 & 1.00 & 0.99 \\
\hline & & 100 & 2.80 & 2.74 & 3.06 & 1.03 & 1.00 & 0.99 \\
\hline \multirow{3}{*}{13} & & 20 & 4.71 & 4.77 & 5.55 & 1.18 & 1.05 & 1.01 \\
\hline & & 50 & 4.66 & 4.71 & 5.52 & 1.17 & 1.05 & 1.01 \\
\hline & & 100 & 4.55 & 4.62 & 5.35 & 1.16 & 1.04 & 1.01 \\
\hline \multirow{3}{*}{19} & & 20 & 6.82 & 7.15 & 8.77 & 1.27 & 1.13 & 1.04 \\
\hline & & 50 & 6.76 & 7.11 & 8.72 & 1.27 & 1.13 & 1.04 \\
\hline & & 100 & 6.59 & 6.96 & 8.51 & 1.27 & 1.12 & 1.03 \\
\hline \multirow{3}{*}{25} & & 20 & 8.90 & 9.75 & 12.03 & 1.35 & 1.23 & 1.07 \\
\hline & 0 & 50 & 8.83 & 9.71 & 11.97 & 1.34 & 1.23 & 1.07 \\
\hline & & 100 & 8.59 & 9.51 & 11.69 & 1.34 & 1.22 & 1.06 \\
\hline \multirow{3}{*}{50} & & 20 & 17.64 & 20.18 & 25.46 & 1.67 & 1.40 & 1.25 \\
\hline & & 50 & 17.54 & 20.15 & 25.38 & 1.66 & 1.39 & 1.25 \\
\hline & & 100 & 17.14 & 19.87 & 24.87 & 1.65 & 1.39 & 1.25 \\
\hline \multirow{3}{*}{90} & & 20 & 31.48 & 36.29 & 46.22 & 2.04 & 1.66 & 1.39 \\
\hline & & 50 & 31.17 & 36.25 & 46.09 & 2.04 & 1.66 & 1.39 \\
\hline & & 100 & 30.63 & 35.71 & 45.37 & 2.02 & 1.64 & 1.39 \\
\hline \multirow{3}{*}{120} & & 20 & 41.79 & 48.28 & 61.58 & 2.25 & 1.83 & 1.49 \\
\hline & & 50 & 41.63 & 48.25 & 61.52 & 2.25 & 1.83 & 1.49 \\
\hline & & 100 & 40.81 & 47.54 & 60.44 & 2.23 & 1.81 & 1.48 \\
\hline \multirow{3}{*}{169} & & 20 & 58.98 & 67.89 & 86.59 & 2.53 & 2.05 & 1.67 \\
\hline & & 50 & 58.65 & 67.85 & 86.50 & 2.52 & 2.05 & 1.66 \\
\hline & & 100 & 57.50 & 66.87 & 85.13 & 2.50 & 2.03 & 1.65 \\
\hline
\end{tabular}

Table 10 shows the results of lightning-induced voltage when the single DC SPD Class II was installed close to the inverter on the DC side. There are two measurement points, denoted as point A (solar PV and battery) and point B (DC side of the inverter). The results obtained were compared with the impulse withstand voltage, and the quantifying analysis was explained in each of Sections 5.1-5.3. Considering the impulse withstand voltage of equipment on the DC side is $6 \mathrm{kV}$, as per standard PD CLC/TS 50539-12, one can clearly see that the recorded induced voltage exceeds the limit of $6 \mathrm{kV}$ when the current is greater than, or equal to, $25 \mathrm{kA}$, regardless of the strike distance. As for the inverter on the DC side, it is properly protected by the SPD Class II below the withstand limit.

Next, Table 11 shows the results of lightning-induced voltage when the single AC SPD Class II was installed close to the transformer. There are two measurement points, denoted as point $\mathrm{C}$ (near inverter on $\mathrm{AC}$ side) and point $\mathrm{D}$ (transformer). Likewise, in this case, 
results obtained were also compared with the impulse withstand voltage, as mentioned in Sections 5.1-5.3. i.e., $2.5 \mathrm{kV}$ and $4 \mathrm{kV}$ for the inverter and $\mathrm{LV}$ transformer, respectively.

Again, results indicate that the installation of AC SPD Class II close to the transformer was able to protect from the potential damage. As for the AC side of the inverter, any current of greater than $3 \mathrm{kA}$ has caused the induced voltage to exceed the withstand limit of $2.5 \mathrm{kV}$, regardless of strike distance cable lengths. Therefore, it is obvious that the AC SPD is clearly needed for protecting the equipment, despite that the location of less than $10 \mathrm{~m}$ does not require an SPD installation, as highlighted in the IEC TR 63227 and PD CLC/TS 50539-12. Hence, depending on the local lightning data, one can have a very good idea of selecting an appropriate rating and lightning protection level for their system.

\subsection{Effect of Different Lightning Strike Distance}

This section discusses the effect of lightning-induced voltage when the lightning current amplitude of $19 \mathrm{kA}$ strikes nearby the $10 \mathrm{~m}$ cable of the system with varying the lightning strike distances (i.e., $d=20 \mathrm{~m}, 50 \mathrm{~m}, 100 \mathrm{~m}$ away from the system) with the SPD Class II installed on both DC and AC sides. Figure 11a shows the solar PV-battery can withstand the induced voltage since it is less than the $6 \mathrm{kV}$ of maximum impulse withstand voltage for solar PV-battery at the DC side. Figure $11 \mathrm{~b}$ shows the inverter on the DC side is properly protected by the single installation of DC SPD Class II. Meanwhile, Figure 11c shows the induced voltage near the inverter, on the $\mathrm{AC}$ side, has exceeded the impulse withstand voltage of $2.5 \mathrm{kV}$. However, Figure 11d presents the AC SPD Class II was able to clamp the induced voltage near the transformer.

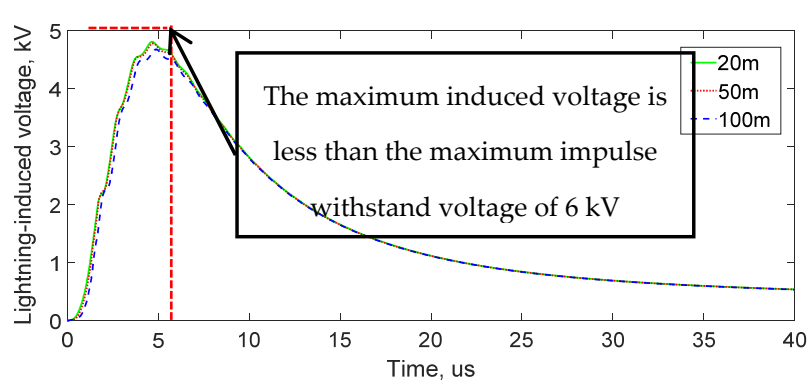

(a) Point A

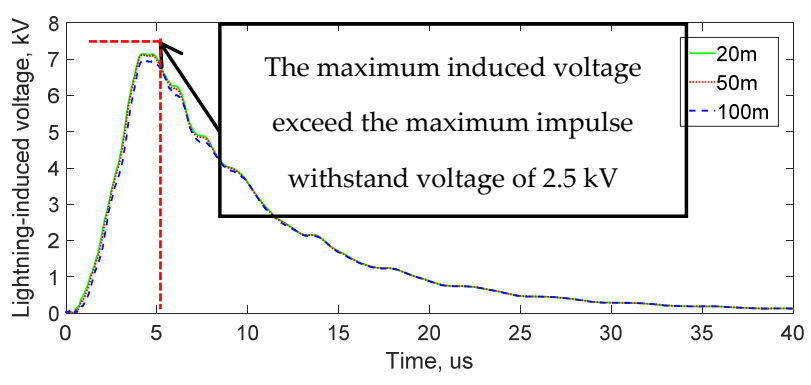

(c) Point C

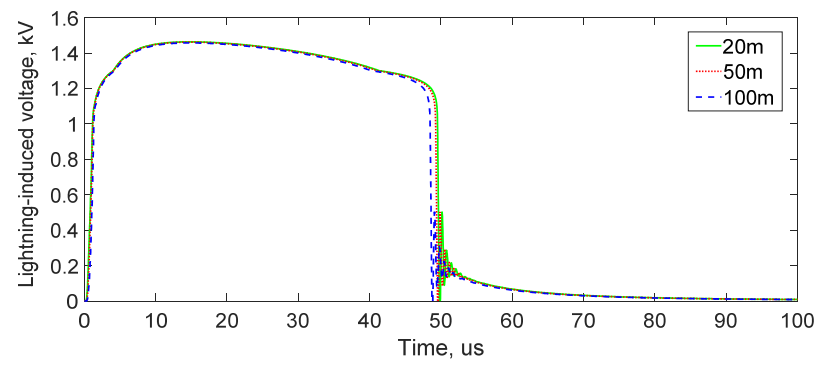

(b) Point B

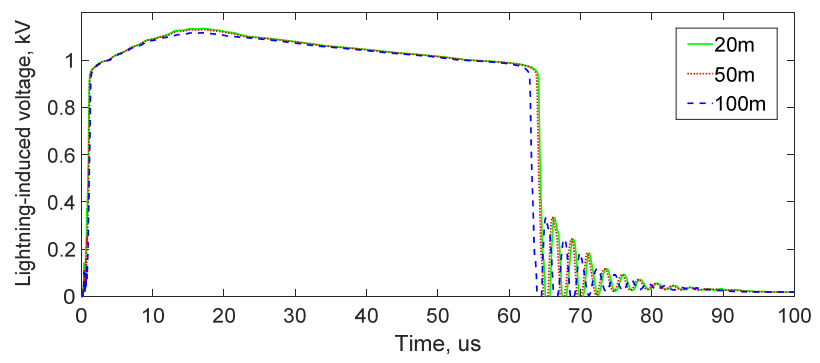

(d) Point D

Figure 11. Lightning-induced voltage at $x=0\left(d=20 \mathrm{~m}, 50 \mathrm{~m}, 100 \mathrm{~m}, I_{0}=19 \mathrm{kA}, \beta=0.4\right)$ at four measurement points. Point A (near the solar PV and battery); Point B (near the DC inverter); Point C (near the AC inverter); Point D (near the transformer).

Tables 12 and 13 present the percentage difference of clamped induced voltage by comparing the data without, and with, SPD Class II installation at both DC and AC sides. Table 12 shows that, with the single installation of DC SPD Class II installed near the inverter on the DC side, the measurement of lightning-induced voltages at point $\mathrm{A}$ was about $25.08 \%$ at $20 \mathrm{~m}, 24.96 \%$ at $50 \mathrm{~m}$, and $24.64 \%$ at $100 \mathrm{~m}$. Meanwhile, it is a different case at point $B$ where the clamped lightning-induced voltages were about $77.26 \%$ to $76.49 \%$ as the lightning strike distance increases. From this observation, it can be seen that with the 
single installation of DC SPD Class II near the inverter, the solar PV-battery can withstand the impulse withstand voltage of $6 \mathrm{kV}$.

Table 12. Percentage difference at measurement Point A and B on DC side.

\begin{tabular}{|c|c|c|c|c|c|c|c|}
\hline \multirow{3}{*}{$\begin{array}{l}\text { Lightning } \\
\text { Current, } I_{0}(\mathrm{kA})\end{array}$} & \multirow{3}{*}{$\begin{array}{l}\text { Lightning Strike } \\
\text { Distance, } d(\mathrm{~m})\end{array}$} & \multicolumn{4}{|c|}{ Lightning-Induced Voltage (kV) } & \multirow{2}{*}{\multicolumn{2}{|c|}{$\begin{array}{c}\text { Percentage Difference of Clamped } \\
\text { Induced Voltage between Without and } \\
\text { With SPD (\%) }\end{array}$}} \\
\hline & & \multicolumn{2}{|c|}{ Without DC SPD Class II } & \multicolumn{2}{|c|}{ With DC SPD Class II } & & \\
\hline & & Point A & Point B & Point A & Point B & Point A & Point B \\
\hline \multirow{3}{*}{19} & 20 & 6.42 & 6.42 & 4.81 & 1.46 & 25.08 & 77.26 \\
\hline & 50 & 6.37 & 6.37 & 4.78 & 1.46 & 24.96 & 77.08 \\
\hline & 100 & 6.21 & 6.21 & 4.68 & 1.46 & 24.64 & 76.49 \\
\hline
\end{tabular}

Table 13. Percentage difference at measurement Point $C$ and $D$ on $A C$ side.

\begin{tabular}{|c|c|c|c|c|c|c|c|}
\hline \multirow{3}{*}{$\begin{array}{c}\text { Lightning } \\
\text { Current, } I_{0}(\mathbf{k A})\end{array}$} & \multirow{3}{*}{$\begin{array}{l}\text { Lightning Strike } \\
\text { Distance, } d(\mathrm{~m})\end{array}$} & \multicolumn{4}{|c|}{ Lightning-Induced Voltage (kV) } & \multirow{2}{*}{\multicolumn{2}{|c|}{$\begin{array}{c}\text { Percentage Difference of Clamped } \\
\text { Induced Voltage between Without and } \\
\text { With SPD (\%) }\end{array}$}} \\
\hline & & \multicolumn{2}{|c|}{ Without AC SPD Class II } & \multicolumn{2}{|c|}{ With AC SPD Class II } & & \\
\hline & & Point C & Point D & Point C & Point D & Point C & Point D \\
\hline \multirow{3}{*}{19} & 20 & 6.94 & 6.88 & 7.15 & 1.13 & 3.03 & 83.58 \\
\hline & 50 & 6.85 & 6.81 & 7.11 & 1.13 & 3.80 & 83.41 \\
\hline & 100 & 6.68 & 6.65 & 6.96 & 1.12 & 4.19 & 83.16 \\
\hline
\end{tabular}

Meanwhile, Table 13 presents the single installation of AC SPD Class II near the transformer, the measurement of lightning-induced voltages at point $C$ was about $3.03 \%$ at $20 \mathrm{~m}, 3.80 \%$ at $50 \mathrm{~m}$, and $4.19 \%$ at $100 \mathrm{~m}$. However, the lightning-induced voltages, measured at point $\mathrm{D}$, were from $83.58 \%$ to $83.16 \%$ with increasing lightning strike distance from $20 \mathrm{~m}$ to $100 \mathrm{~m}$. In this case, a single installation of AC SPD Class II is not enough to protect the inverter on the AC side since it is exceeded $2.5 \mathrm{kV}$ of impulse withstand voltage.

Based on the results obtained, it can be seen that the solar PV-battery was in a safe zone only up to $19 \mathrm{kA}$ of lightning current amplitude at lightning strike distances of $20 \mathrm{~m}$ and $50 \mathrm{~m}$. For $100 \mathrm{~m}$, the solar PV-battery was protected only up to $25 \mathrm{kA}$. High lightning-induced voltages were observed at the solar PV-battery when the lightning current amplitude is more than $25 \mathrm{kA}$. However, it is different for the inverter on the AC side, which is protected only up to $3 \mathrm{kA}$ at all lightning strike distances. Hence, based on the analysis of percentage difference, one can clearly see that when the lightning current amplitude is $19 \mathrm{kA}$, the single SPD Class II at the DC side able to clamp a maximum of $25 \%$ of induced voltage at solar PV-battery whilst only $3 \%$ to $4 \%$ of clamped induced voltage at the AC inverter.

Results showed that as the lightning strike distances are increased, the percentage difference of clamped induced voltage without, and with, SPD on the DC side at points $\mathrm{A}$ and $\mathrm{B}$ decreases. It is the same as on the $\mathrm{AC}$ side whereby the percentage difference of clamped induced voltage without, and with, SPD at points $C$ and D also decrease as the lightning strike distance is increased.

\subsection{Effect of Different Lightning Currents Amplitude}

This section discusses the effect of different lightning-induced voltage with varied lightning current amplitude (i.e., $3 \mathrm{kA}$ to $169 \mathrm{kA}$ ) when lightning strikes $50 \mathrm{~m}$ away from the system and cable length is $10 \mathrm{~m}$ with the single installation of SPD Class II on both DC and AC sides. Figure 12a shows the solar PV-battery is in the safe zone for only up to $25 \mathrm{kA}$ of lightning current amplitude with a single installation of DC SPD Class II near to the inverter on the DC side. If the lightning current amplitude is more than $25 \mathrm{kA}$, the induced voltage may exceed the $6 \mathrm{kV}$ of impulse withstand voltage for the solar PV-battery. Figure $12 \mathrm{~b}$ presents the inverter is properly protected with a single installation of DC SPD Class II. Figure 12c also depicts that the inverter on the AC side is able to withstand 
$2.5 \mathrm{kV}$ of impulse withstand voltage for only up to approximately $5 \mathrm{kA}$ of lightning current amplitude. Meanwhile, Figure $12 \mathrm{~d}$ demonstrates the induced voltage was able to be reduced with a single installation of AC SPD Class II near the transformer.

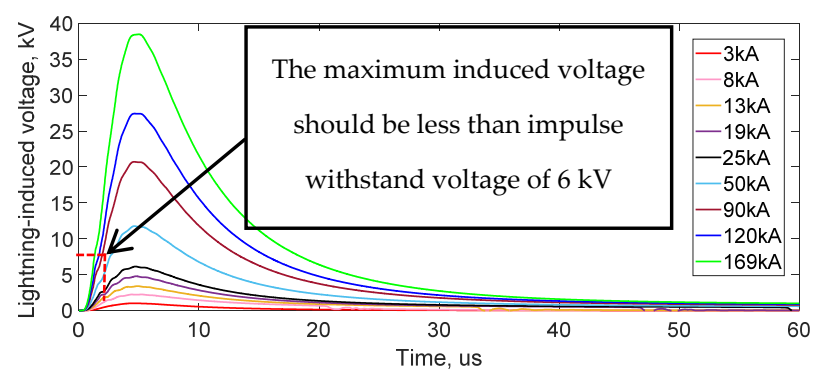

(a) Point A

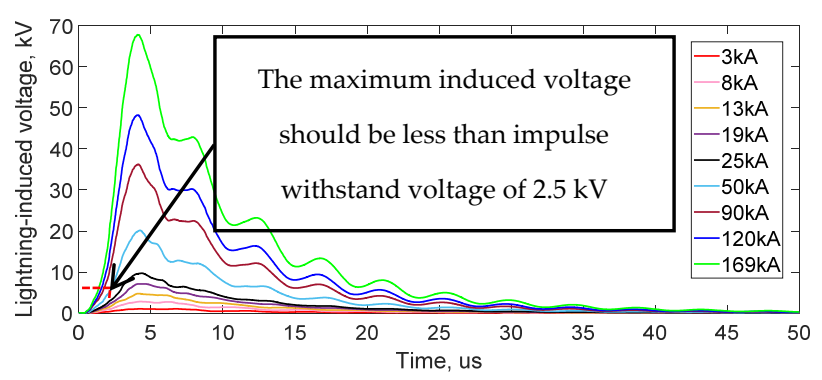

(c) Point C

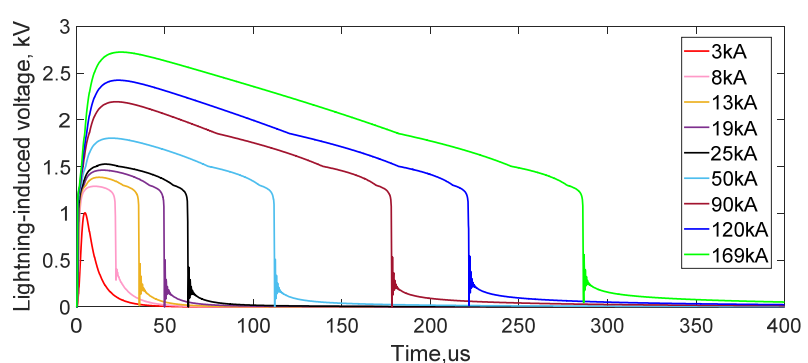

(b) Point B

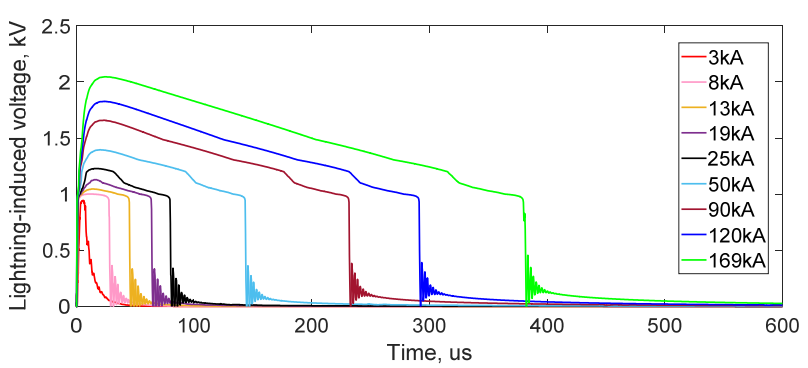

(d) Point D

Figure 12. Lightning-induced voltage at $x=0\left(d=50 \mathrm{~m}, I_{0}=3 \mathrm{kA}-169 \mathrm{kA}, \beta=0.4\right)$ at four measurement points. Point A (near the solar PV and battery); Point B (near the DC inverter); Point C (near the AC inverter); Point D (near the transformer).

Tables 14 and 15 present the percentage difference of clamped induced voltage by comparing the data without and with SPD Class II installation on both DC and AC sides. In this section, only three lightning current amplitudes were selected based on the statistical analysis at the Solar PV farm, Puchong [28]. It represents the probability of 5\%,50\%, and $95 \%$ of lightning current amplitude occurrence according to the International Council on Large Electric Systems (CIGRE) [45].

Table 14. Percentage difference at measurement Point A and B on DC side.

\begin{tabular}{|c|c|c|c|c|c|c|c|}
\hline \multirow{3}{*}{$\begin{array}{c}\text { Lightning Current, } \\
I_{0}(\mathrm{kA})\end{array}$} & \multirow{3}{*}{$\begin{array}{l}\text { Lightning Strike } \\
\text { Distance, } d(\mathrm{~m})\end{array}$} & \multicolumn{4}{|c|}{ Lightning-Induced Voltage (kV) } & \multirow{2}{*}{\multicolumn{2}{|c|}{$\begin{array}{l}\text { Percentage Difference of Clampec } \\
\text { Induced Voltage between Withou } \\
\text { and With SPD (\%) }\end{array}$}} \\
\hline & & \multicolumn{2}{|c|}{ Without DC SPD Class II } & \multicolumn{2}{|c|}{ With DC SPD Class II } & & \\
\hline & & Point A & Point B & Point A & Point B & Point A & Point B \\
\hline 3 & \multirow{3}{*}{50} & 1.02 & 1.01 & 1.02 & 1.01 & 0 & 0 \\
\hline 19 & & 6.37 & 6.37 & 4.78 & 1.46 & 24.96 & 77.08 \\
\hline 169 & & 56.65 & 56.65 & 38.43 & 2.72 & 32.16 & 95.20 \\
\hline
\end{tabular}

Table 15. Percentage difference at measurement Point $C$ and D on AC side.

\begin{tabular}{|c|c|c|c|c|c|c|c|}
\hline \multirow{3}{*}{$\begin{array}{c}\text { Lightning Current, } \\
I_{0}(\mathrm{kA})\end{array}$} & \multirow{3}{*}{$\begin{array}{l}\text { Lightning Strike } \\
\text { Distance, } d(\mathrm{~m})\end{array}$} & \multicolumn{4}{|c|}{ Lightning-Induced Voltage (kV) } & \multirow{2}{*}{\multicolumn{2}{|c|}{$\begin{array}{l}\text { Percentage Difference of Clamped } \\
\text { Induced Voltage between Without } \\
\text { and With SPD (\%) }\end{array}$}} \\
\hline & & \multicolumn{2}{|c|}{ Without AC SPD Class II } & \multicolumn{2}{|c|}{ With AC SPD Class II } & & \\
\hline & & Point C & Point D & Point C & Point D & Point C & Point D \\
\hline 3 & \multirow{3}{*}{50} & 1.06 & 1.06 & 1.04 & 0.94 & 1.89 & 11.32 \\
\hline 19 & & 6.85 & 6.81 & 7.11 & 1.13 & 3.80 & 83.41 \\
\hline 169 & & 61.28 & 60.34 & 67.85 & 2.05 & 10.72 & 96.60 \\
\hline
\end{tabular}


Table 14 shows that with a single installation of DC SPD Class II near the inverter on the DC side, the measurement of the lightning-induced voltage at points A and B shows that the system is safe even without the SPD Class II for the lightning current amplitude of $3 \mathrm{kA}$. For lightning current amplitude of $19 \mathrm{kA}$, the lightning-induced voltage has been clamped for about $24.96 \%$ at point $\mathrm{A}$ and $77.08 \%$ at point $\mathrm{B}$. Whilst for the lightning current amplitude of $169 \mathrm{kA}$, the lightning-induced voltage has reduced to about $32.16 \%$ at point $\mathrm{A}$ and $95.20 \%$ at point B. However, in the case of $169 \mathrm{kA}$, the single installation of DC SPD Class II is not sufficient and may harm the system since it exceeded the impulse withstand voltage of $2.5 \mathrm{kV}$.

Meanwhile, Table 15 shows that with the single installation of AC SPD Class II near the transformer, the measurement of the lightning-induced voltage at point $\mathrm{C}$ shows about $1.89 \%$ for $3 \mathrm{kA}, 3.80 \%$ for $19 \mathrm{kA}$, and $10.72 \%$ for $169 \mathrm{kA}$ were able to be clamped by AC SPD Class II. Whilst at point D, about $11.32 \%$ for $3 \mathrm{kA}, 83.41 \%$ for $19 \mathrm{kA}$, and $96.60 \%$ for $169 \mathrm{kA}$ have successfully been reduced. It can be seen that the transformer is protected since it is not exceeding the impulse withstand voltage of $4 \mathrm{kV}$.

Based on the percentage difference of clamped induced voltage for without, and with, SPD on the DC and AC side, it shows that as the lightning current amplitude increases, the percentage difference also increases. However, the lightning-induced voltage was clamped by single SPD only up to $19 \mathrm{kA}$ of lightning current amplitude at solar PV-battery. If the current is more than $19 \mathrm{kA}$, the maximum clamped induced voltage goes up to $32 \%$ but still exceeding the $6 \mathrm{kV}$ impulse withstand voltage, which may damage the solar PV-battery. Likewise, in the case of the inverter on the AC side, where the single SPD can only clamp up to $3 \mathrm{kA}$. Thus, the inverter is at high risk of being damaged by lightning-induced voltage should it be more than $3 \mathrm{kA}$. In this case, the higher the lightning current amplitude, the higher the lightning-induced voltage obtained, which resulted in rapid rising for the front time and long decaying of tail time. It is described through the lightning current amplitude (peak) value, rise time, and tail time. The tail time is measured as the time taken for the waveform to decay to half of its peak value.

\subsection{Effect of Different Cable Length}

In this case study, the effect of lightning-induced overvoltage with varying cable lengths (i.e., $5 \mathrm{~m}, 10 \mathrm{~m}$, and $20 \mathrm{~m}$ ) at $19 \mathrm{kA}$ lightning current amplitude and $50 \mathrm{~m}$ lightning stroke distance away from the system is investigated. An SPD Class II was installed at the DC and AC sides, respectively. Figure 13a shows that the solar PV-battery was protected from the lightning-induced voltage for all selected cable lengths since the induced voltage is less than $6 \mathrm{kV}$ of impulse withstand voltage. Whilst Figure 13b shows that the inverter was protected by the single installation of DC SPD Class II.

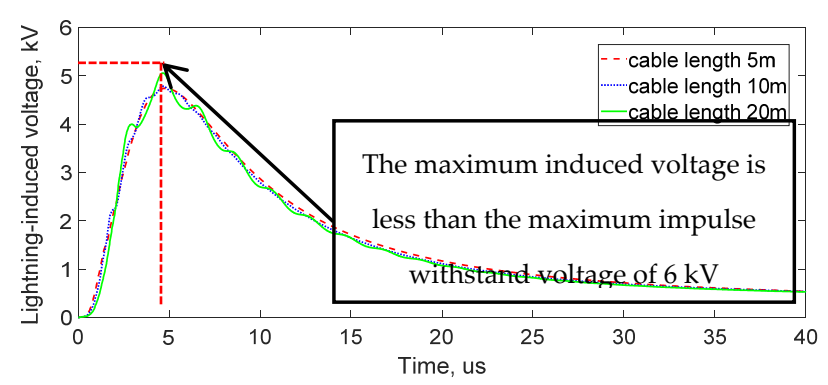

(a) Point A

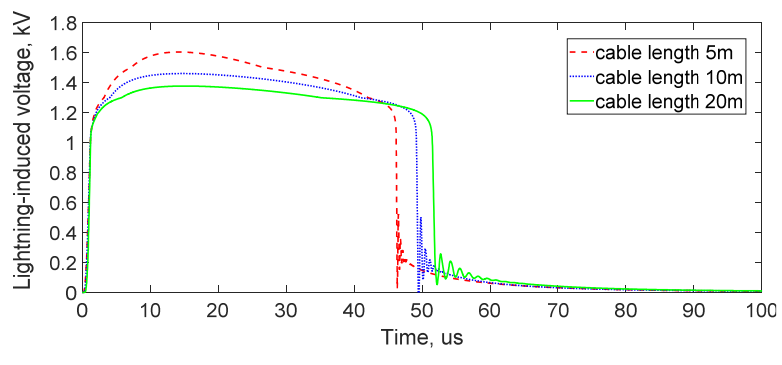

(b) Point B

Figure 13. Cont. 


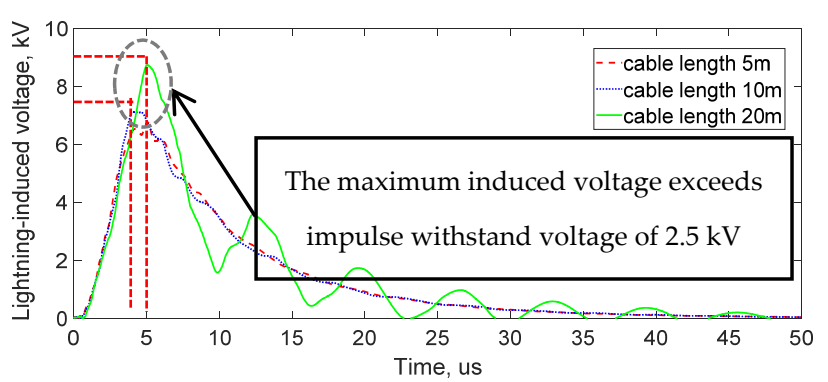

(c) Point C

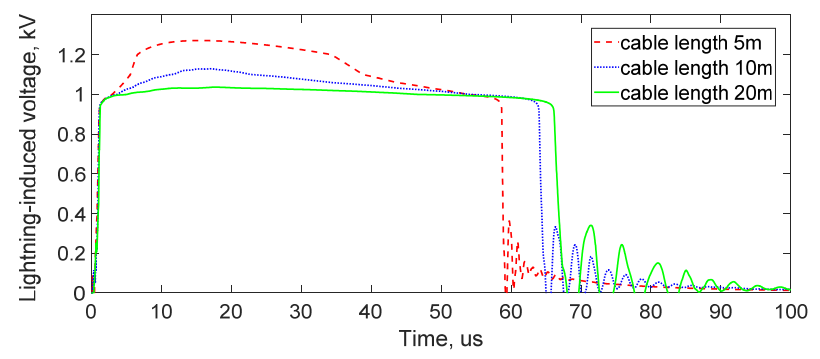

(d) Point D

Figure 13. Lightning-induced voltage at $x=0\left(d=50 \mathrm{~m}, I_{0}=19 \mathrm{kA}\right.$, cable length $\left.=5 \mathrm{~m}, 10 \mathrm{~m}, 20 \mathrm{~m}, \beta=0.4\right)$ at four measurement points. Point A (near the solar PV and battery); Point B (near the DC inverter); Point C (near the AC inverter); Point D (near the transformer).

Figure $13 \mathrm{c}$ shows that the inverter on the AC side was damaged, due to the induced voltage, which has exceeded the impulse withstand voltage of $2.5 \mathrm{kV}$ and $4 \mathrm{kV}$. However, with the single installation of AC SPD Class II near the transformer, the induced voltage near the transformer has fully been clamped by the SPD as shown in Figure 13d.

The percentage difference of resulting induced voltage measured with, and without, SPD installation at both DC and AC sides are tabulated in Tables 16 and 17, respectively. Table 16 shows that with a single installation of DC SPD Class II near the inverter on the DC side, the lightning-induced voltages were clamped at point $A$ for about $25.71 \%$ for $5 \mathrm{~m}, 25.43 \%$ for $10 \mathrm{~m}$, and $25.37 \%$ for $20 \mathrm{~m}$. It is the same for the case measured at point B whereby about $74.73 \%$ for $5 \mathrm{~m}, 77.12 \%$ for $10 \mathrm{~m}$, and $79.40 \%$ for $20 \mathrm{~m}$. Thus, it showed that the equipment on the DC side was protected with a single installation of DC SPD Class II near the inverter.

Table 16. Percentage difference at measurement Point A and B on DC side.

\begin{tabular}{|c|c|c|c|c|c|c|c|c|}
\hline \multirow{3}{*}{$\begin{array}{l}\text { Lightning } \\
\text { Current, } \\
I_{0}(\mathrm{kA})\end{array}$} & \multirow{3}{*}{$\begin{array}{l}\text { Lightning } \\
\text { Strike } \\
\text { Distance, } \\
d(\mathrm{~m})\end{array}$} & \multirow{3}{*}{$\begin{array}{c}\text { Cable } \\
\text { Length, m }\end{array}$} & \multicolumn{4}{|c|}{ Lightning-Induced Voltage (kV) } & \multirow{2}{*}{\multicolumn{2}{|c|}{$\begin{array}{l}\text { Percentage Difference of Clamped } \\
\text { Induced Voltage between Without } \\
\text { and With SPD (\%) }\end{array}$}} \\
\hline & & & \multicolumn{2}{|c|}{ Without DC SPD Class II } & \multicolumn{2}{|c|}{ With DC SPD Class II } & & \\
\hline & & & Point A & Point B & Point A & Point B & Point A & Point B \\
\hline \multirow{3}{*}{19} & \multirow{3}{*}{50} & 5 & 6.38 & 6.37 & 4.74 & 1.61 & 25.71 & 74.73 \\
\hline & & 10 & 6.41 & 6.38 & 4.78 & 1.46 & 25.43 & 77.12 \\
\hline & & 20 & 6.78 & 6.70 & 5.06 & 1.38 & 25.37 & 79.40 \\
\hline
\end{tabular}

Table 17. Percentage difference at measurement Point $C$ and $D$ on $A C$ side.

\begin{tabular}{|c|c|c|c|c|c|c|c|c|}
\hline \multirow{3}{*}{$\begin{array}{l}\text { Lightning } \\
\text { Current, } I_{0} \\
\quad \text { (kA) }\end{array}$} & \multirow{3}{*}{$\begin{array}{l}\text { Lightning } \\
\text { Strike } \\
\text { Distance, } \\
d(\mathrm{~m})\end{array}$} & \multirow{3}{*}{$\begin{array}{c}\text { Cable } \\
\text { Length, } \mathrm{m}\end{array}$} & \multicolumn{4}{|c|}{ Lightning-Induced Voltage (kV) } & \multirow{2}{*}{\multicolumn{2}{|c|}{$\begin{array}{c}\text { Percentage Difference of Clamped } \\
\text { Induced Voltage between Without } \\
\text { and With SPD (\%) }\end{array}$}} \\
\hline & & & \multicolumn{2}{|c|}{ Without AC SPD Class II } & \multicolumn{2}{|c|}{ With AC SPD Class II } & & \\
\hline & & & Point C & Point D & Point C & Point D & Point C & Point D \\
\hline \multirow{3}{*}{19} & \multirow{3}{*}{50} & 5 & 6.97 & 6.86 & 6.76 & 1.27 & 3.01 & 81.49 \\
\hline & & 10 & 6.88 & 6.83 & 7.11 & 1.13 & 3.34 & 83.46 \\
\hline & & 20 & 6.72 & 6.57 & 8.72 & 1.04 & 29.76 & 84.17 \\
\hline
\end{tabular}

Table 17 shows, with a single installation of AC SPD Class II near the transformer, the lightning-induced voltages clamped at point $C$ were recorded about $3.01 \%$ for $5 \mathrm{~m}, 3.34 \%$ for $10 \mathrm{~m}$, and $29.76 \%$ for $20 \mathrm{~m}$. Meanwhile, the measured lightning-induced voltage at point D was about $81.49 \%$ to $84.17 \%$ for $5 \mathrm{~m}$ to $20 \mathrm{~m}$, respectively. Again, a single installation of AC SPD Class II near the transformer was not sufficient enough to protect the inverter at the AC side regardless of any distance.

Therefore, it can be seen that, as the cable lengths are increased, the percentage difference of clamped induced voltage for without, and with, SPD at points A and C are also decreased. However, the percentage difference of clamped induced voltage obtained 
for without and with SPD at points B and D (where SPD is located) has increased as the cable lengths are increased. Overall, the cable length between the SPD installation point and equipment to be protected are of great importance in terms of the effectiveness of surge protection. From observation in Figure 13a,c, the farther the distance between SPD and the equipment to be protected, more than $10 \mathrm{~m}$ in this case, the higher the lightning-induced voltage recorded. This is due to the overvoltage and electromagnetic oscillations that lead to a higher induced voltage measured at the equipment to be protected [53-55]. Hence, the failure on the equipment to be protected may happen despite the presence of SPD. However, the oscillations may be neglected for cable length less than $10 \mathrm{~m}$ from the SPD since the SPD installation should be kept as close as possible to the equipment to be protected.

Based on the analysis in all sections, the lightning-induced voltage was travelled and caused overvoltage in the system, which leads to crucial damage and equipment inefficiency especially solar PV, battery energy storage, inverter, etc. [21,23,42,56]. Therefore, throughout all the case studies, the distant the certain equipment/device from the SPD, the lower the percentage of reduction in clamped induced voltage between without, and with, SPD in the system. As referred to the standard IEC TR 63227, it is recommended that more than one SPD Class II, in a system without external LPS, is required to be installed directly at the equipment to be protected due to the following reasons:

- The closer the lightning strike distance, the higher the induced voltage on the system.

- The higher the lightning current amplitude, the higher the induced voltage generated.

- The longer the cable, the higher the induced voltage produced to the system.

However, as referred to the standard IEC TR 63227 and PD CLC/TS 50539-12, there is no adequate information on impulse withstand voltage requirement or basic insulation level (BIL) for battery energy storage as there are not many studies available, especially related to lightning-induced voltage studies. Therefore, by having the above results, it also becomes part of the contribution for the International Council on Large Electric Systems Working Group Committees 4.44 (CIGRE WG C4.44) on Electromagnetic Compatibility (EMC) for Large Photovoltaic Systems. In addition, it is also recommended to further investigate the SPD's capability of clamping impulse voltage by using the different SPD types and configurations, as stated in standard PD CLC/TS 50539-12, in the next study.

\section{Conclusions}

In conclusion, this paper presented the effect of lightning-induced voltage on a hybrid solar PV-battery energy storage system through a single installation of SPD at both DC and AC sides. In this work, it is proven that the single installation of SPD in the system is not enough to fully protect the equipment. The single installation of SPD, near the inverter on the DC side, causes the solar PV-battery to withstand impulse voltage of $6 \mathrm{kV}$ only up to $19 \mathrm{kA}$, regardless of any lightning strike distances and cable lengths and up to $25 \mathrm{kA}$ at $100 \mathrm{~m}$ lightning strike distance for $5 \mathrm{~m}$ cable only. Meanwhile, regardless of the lightning strike distances for cable length $10 \mathrm{~m}$ and $20 \mathrm{~m}$, the withstand impulse voltage is up to $19 \mathrm{kA}$. With a single installation of AC SPD near the transformer, the inverter on the AC side can withstand impulse voltage of $2.5 \mathrm{kV}$ only up to $3 \mathrm{kA}$, regardless of the lightning strike distances (from $20 \mathrm{~m}$ to $100 \mathrm{~m}$ ) and cable lengths ( $5 \mathrm{~m}$ to $20 \mathrm{~m}$ ). The major contributions of this work contributed to the quantified results of induced voltage, based on the sensitivity analysis carried out from the three case studies in Sections 5.1-5.3. Taking into account the withstanding voltages of the equipment, one can clearly see the probability of damage to the equipment, particularly to the inverter, when each of the parameters is varied.

This kind of problem may lead to fluctuations and unstable generation output which causes profit loss to the customer. Therefore, to ensure the system is able to operate in maximum efficiency along with operation, without any constraint, the SPD is required to be properly installed and coordinated based on the published standard PD CLC/TS 5053912 [31] and IEC TR 63227 [33], taking into account all the results presented in this study. Owing to the criticality of the solar farm, in terms of protection and productivity, several im- 
portant criteria, such as the placement, rating, and quantity of SPD needed have to be taken into account. These aspects govern the performance evaluation of the equipment when comparing with its withstanding Basic Lightning Insulation Level (BIL). Consequently, an appropriate protection scheme shall be assigned and coordinated accordingly upon the proper installation.

Author Contributions: Conceptualization, N.I.A. and M.Z.A.A.K.; methodology, N.I.A.; software, N.I.A. and M.H.R.; validation, N.I.A.; formal analysis, N.I.A.; investigation, N.I.A., Z.A. and M.Z.A.A.K.; resources, N.I.A. and N.H.Z.; data curation, N.I.A.; writing-original draft preparation, N.I.A.; writing—review and editing, Z.A. and M.Z.A.A.K.; visualization, N.I.A.; supervision, Z.A., M.Z.A.A.K. and M.O.; project administration, Z.A., M.Z.A.A.K. and M.O.; funding acquisition, Z.A., M.Z.A.A.K. and M.O. All authors have read and agreed to the published version of the manuscript.

Funding: This research and APC was funded by Ministry of Higher Education, Fundamental Research Grant Scheme (FRGS) scheme, grant number FRGS/1/2018/TK07/UNITEN/02/5.

Institutional Review Board Statement: Not applicable.

Informed Consent Statement: Not applicable.

Data Availability Statement: Not applicable.

Acknowledgments: The authors would like to express their sincere gratitude to the Ministry of Higher Education, Institute Power Engineering, and Building Opportunity Leading Dreams (BOLD) Scholarship of Universiti Tenaga Nasional (UNITEN).

Conflicts of Interest: The authors declare no conflict of interest. The funders had no role in the design of the study; in the collection, analyses, or interpretation of data; in the writing of the manuscript, or in the decision to publish the results.

\section{References}

1. Ab Kadir, M.Z.A.; Rafeeu, Y.; Adam, N.M. Prospective scenarios for the full solar energy development in Malaysia. Renew. Sustain. Energy Rev. 2010, 14, 3023-3031. [CrossRef]

2. Gielen, D.; Boshell, F.; Saygin, D.; Bazilian, M.D.; Wagner, N.; Gorini, R. The role of renewable energy in the global energy transformation. Energy Strategy Rev. 2019, 24, 38-50. [CrossRef]

3. Mukund, R.P. Wind and Solar Power Systems-Design, Analysis and Operation; CRC Press: Boca Raton, FL, USA, $2006 ;$ pp. 143-148.

4. Mekhilef, S.; Safari, A.; Mustaffa, W.; Saidur, R.; Omar, R.; Younis, M. Solar energy in Malaysia: Current state and prospects. Renew. Sustain. Energy Rev. 2012, 16, 386-396. [CrossRef]

5. Ho, S.M.; Lomi, A.; Okoroigwe, E.C.; Urrego, L.R. Investigation of solar energy: The case study in Malaysia, Indonesia, Colombia and Nigeria. Int. J. Renew. Energy Res. 2019, 9, 1-10.

6. Sustainable Energy Development Authority Malaysia (SEDA). Available online: http://www.seda.gov.my/reportal/re-incentive/ (accessed on 13 November 2020).

7. National Survey Report of PV Power Applications in Malaysia 2019. Available online: https://iea-pvps.org/wp-content/ uploads /2020/08/NSR_Malaysia_2019.pdf (accessed on 15 March 2021).

8. Vaka, M.; Walvekar, R.; Rasheed, A.K.; Khalid, M. A review on Malaysia's solar energy pathway towards carbon-neutral Malaysia beyond Covid'19 pandemic. J. Clean. Prod. 2020, 273, 122834. [CrossRef] [PubMed]

9. Shirowzhan, S.; Tan, W.; Sepasgozar, S.M. Digital twin and CyberGIS for improving connectivity and measuring the impact of infrastructure construction planning in smart cities. Int. J. Geo. Inf. 2020, 9, 240. [CrossRef]

10. Desdemoustier, J.; Crutzen, N.; Giffinger, R. Municipalities' understanding of the Smart City concept: An exploratory analysis in Belgium. Technol. Forecast. Soc. Chang. 2019, 142, 129-141. [CrossRef]

11. Subramani, G.; Ramachandaramurthy, V.K.; Padmanaban, S.; Mihet-Popa, L.; Blaabjerg, F.; Guerrero, J.M. Grid-tied photovoltaic and battery storage systems with Malaysian electricity tariff-A review on maximum demand shaving. Energies 2017, 10, 1884. [CrossRef]

12. Izadi, M.; Ab Kadir, M.Z.A.; Hajikhani, M. On the lightning induced voltage along overhead power distribution line. J. Electr. Eng. Technol. 2014, 9, 1694-1703. [CrossRef]

13. Ab-Kadir, M.Z.A. Lightning severity in Malaysia and some parameters of interest for engineering applications. Therm. Sci. 2016, 20, 437-450. [CrossRef]

14. Ab Kadir, M.; Misbah, N.R.; Gomes, C.; Jasni, J.; Ahmad, W.W.; Hassan, M. Recent statistics on lightning fatalities in Malaysia. In Proceedings of the International Conference on Lightning Protection (ICLP), Vienna, Austria, 2-7 September 2012 ; pp. 1-5.

15. Lightning and Surge Protection of SSEG Installations. Available online: https://www.ee.co.za/wp-content/uploads/2018/10/ Hano-Oelofse-DEHN-africa-presentation.pdf (accessed on 1 December 2019). 
16. Malaysia's Lightning Strikes: A Spectacular If Dangerous Show. Available online: https://www.freemalaysiatoday.com/ category/leisure/2020/03/29/malaysias-lightning-strikes-a-spectacular-if-dangerous-show/ (accessed on 10 March 2021).

17. Malaysians Unprepared for Lightning Strikes. Available online: https://www.thestar.com.my/news/nation/2018/11/10 /msians-unprepared-for-lightning-strikes-expert-many-lack-awareness-and-safety-measures/ (accessed on 10 March 2021).

18. Zaini, N.H.; Ab-Kadir, M.Z.A.; Radzi, M.A.M.; Izadi, M.; Azis, N.; Ahmad, N.; Nasir, M.S.M. Lightning surge analysis on a large scale grid-connected solar photovoltaic system. Energies 2017, 10, 2149. [CrossRef]

19. Tu, Y.; Zhang, C.; Hu, J.; Wang, S.; Sun, W.; Li, H. Research on lightning overvoltages of solar arrays in a rooftop photovoltaic power system. Electr. Power Syst. Res. 2013, 94, 10-15. [CrossRef]

20. Formisano, A.; Hernández, J.C.; Petrarca, C.; Sanchez-Sutil, F. Modeling of PV Module and DC/DC Converter Assembly for the Analysis of Induced Transient Response Due to Nearby Lightning Strike. Electronics 2021, 10, 120. [CrossRef]

21. Formisano, A.; Petrarca, C.; Hernández, J.C.; Muñoz-Rodríguez, F.J. Assessment of induced voltages in common and differentialmode for a PV module due to nearby lightning strikes. IET Renew. Power Gener. 2019, 13, 1369-1378. [CrossRef]

22. Sun, Q.; Zhong, X.; Liu, J.; Wang, F.; Chen, S.; Zhong, L.; Bian, X. Three-dimensional modeling on lightning induced overvoltage for photovoltaic arrays installed on mountain. J. Clean. Prod. 2021, 288, 125084. [CrossRef]

23. Mohammed, Z.; Hizam, H.; Gomes, C. Lightning-induced transient effects in a hybrid PV-wind system and mitigation strategies. Electr. Power Syst. Res. 2019, 174, 105882. [CrossRef]

24. Nasir, M.; Ab-Kadir, M.; Radzi, M.; Izadi, M.; Ahmad, N.; Zaini, N. Lightning performance analysis of a rooftop grid-connected solar photovoltaic without external lightning protection system. PLoS ONE 2019, 14, 0219326. [CrossRef]

25. Bian, X.; Zhang, Y.; Zhou, Q.; Cao, T.; Wei, B. Numerical and Experimental Study of Lightning Stroke to BIPV Modules. Energies 2021, 14, 748. [CrossRef]

26. Wadhwa, C.L. High Voltage Engineering; New Age International: New Delhi, India, 2006; pp. 237-241.

27. Cooray, G.V. The Lightning Flash; IET: London, UK, 2003; pp. 281-352.

28. Zaini, N.H. Lightning Performance Analysis of a Grid-Connected Solar Photovoltaic System. Ph.D. Thesis, Universiti Putra Malaysia, Selangor, Malaysia, January 2019.

29. Ahmad, N.; Ab-Kadir, M.; Izadi, M.; Azis, N.; Radzi, M.; Zaini, N.; Nasir, M. Lightning protection on photovoltaic systems: A review on current and recommended practices. Renew. Sustain. Energy Rev. 2018, 82, 1611-1619. [CrossRef]

30. Department of Standards Malaysia. Insulation Coordination for Equipment within Low-Voltage Systems-Part 1: Principles, Requirements and Tests; MS IEC 60664-1; Department of Standards Malaysia: Cyberjaya, Selangor, Malaysia, 2014.

31. The British Standards Institution (BSI). Low-Voltage Surge Protective Devices. Surge Protective Devices for Specific Application Including D.C.-Part 12: Selection and Application Principles—SPDs Connected to Photovoltaic Installations; PD CLC/TS 50539-12; BSI: London, UK, 2013.

32. Department of Standards Malaysia. Safety of Power Converters for Use in Photovoltaic Power System; MS IEC 62109-1; Department of Standards Malaysia: Cyberjaya, Selangor, Malaysia, 2011.

33. International Electrotechnical Commission (IEC). Lightning and Surge Voltage Protection for Photovoltaic (PV) Power Supply Systems; IEC TR 63227; IEC: Geneva, Switzerland, 2020.

34. The British Standards Institution (BSI). Low-Voltage Surge Protective Devices-Part 11: Surge Protective Devices Connected to LowVoltage Power Systems-Requirements and Test Methods; BS EN 61643-11: 2012+A11; BSI: London, UK, 2018.

35. The British Standards Institution (BSI). Low-Voltage Surge Protective Devices-Part 31: Requirements and Test Methods for SPDs for Photovoltaic Installations; BS EN 61643-31; BSI: London, UK, 2019.

36. The British Standards Institution (BSI). Lightning Protection System Components (LPSC)—Part 1: Requirements for Connection Components; EN 62561-1; BSI: London, UK, 2012.

37. Zaini, N.H.; Ab-Kadir, M.Z.A.; Radzi, M.A.M.; Izadi, M.; Azis, N.; Ahmad, N.; Nasir, M.S.M. Lightning Surge on the DC and AC Side of Solar PV System. In Proceedings of the Asia-Pacific International Conference on Lightning (APL), Hong Kong, China, 12-14 June 2019; pp. 1-5.

38. Sabiha, N.A. Lightning-Induced Overvoltages in Medium Voltage Distribution Systems. Ph.D. Thesis, Aalto University, Espoo, Finland, 18 March 2010.

39. Kannu, P.D.; Thomas, M.J. Influence of Lightning Strike Location on The Induced Voltage on a Nearby Overhead Line. In Proceedings of the Conference on National Power Systems, Kharagpur, India, 27-29 December 2002; pp. 1-6.

40. Paolone, M. Modeling of Lightning-Induced Voltages on Distribution Networks for the Solution of Power Quality Problem. Ph.D. Thesis, University of Bologna, Bologna, Italy, 1998-2001.

41. The British Standards Institution (BSI). Protection against lightning-Part 1: General Principles; BS EN 62305-1; BSI: London, UK, 2011.

42. Ahmad, N.I.; Ali, Z.; Ab-Kadir, M.Z.K.; Osman, M.; Zaini, N.; Roslan, M.H. Impacts of Lightning-Induced Overvoltage on a Hybrid Solar PV-Battery Energy Storage System. Appl. Sci. 2021, 11, 3633. [CrossRef]

43. The British Standards Institution (BSI). Protection Against Lightning-Part 4: Electrical and Electronic Systems within Structures; BS EN 62305-4; BSI: London, UK, 2011.

44. The ABC's of Lightning. Available online: http:/ / www.dehn-usa.com (accessed on 22 March 2021).

45. Rakov, V.A.; Borghetti, A.; Bouquegneau, C.; Chisholm, W.A.; Cooray, V.; Cummins, K. CIGRE Lightning Parameters for Engineering Applications; CIGRE Working Group C4.407; CIGRE: Paris, France, 2013; pp. 1-118.

46. Rakov, V.A.; Uman, M.A. Lightning: Physics and Effects; Cambridge University Press: Cambridge, UK, 2003 ; pp. 617-618. 
47. Cooray, V. Lightning Protection; The Institution of Engineering and Technology: London, UK, 2009; pp. 573-574.

48. Institute of Electrical and Electronics Engineers (IEEE). IEEE Guide for Improving the Lightning Performance of Electric Power Overhead Distribution Lines; IEEE 1410-2004; IEEE: New York, NY, USA, 2010.

49. Lightning and Surge Protection Basics. Available online: https://www.phoenixcontact.com/assets/downloads_ed/global/web_ dwl_promotion/5131327_TT_Basics_EN.pdf (accessed on 9 April 2021).

50. Data Assessment for Electrical Surge Protection Devices. Available online: https://www.nfpa.org/-/media/Files/News-and-Research/ Fire-statistics-and-reports/Electrical/RFDataAssessmentforElectricalSurgeProtectionDevices.ashx (accessed on 9 April 2021).

51. Type 2 Surge Protection Plug-VAL-MS 1000DC-PV-ST-2800624 Datasheet. Available online: https:/ /www.phoenixcontact.com/ online/portal/us?uri=pxc-oc-itemdetail:pid=2800624\&library=usen\&tab=1 (accessed on 12 April 2021).

52. Product Data Sheet: DEHNguard®Modular (DG M TNS 275 FM (952 405). Available online: https: / / docs.rs-online.com/ c94b / 0900766b8138a9c1.pdf (accessed on 20 April 2021).

53. Liu, C.H.; Muna, Y.B.; Chen, Y.T.; Kuo, C.C.; Chang, H.Y. Risk analysis of lightning and surge protection devices for power energy structures. Energies 2019, 11, 1999. [CrossRef]

54. Guide to Surge Protection Devices. Available online: https://www.hager.co.uk/files/download/0/4540_1/0/Surge_Protection_ Guide.pdf (accessed on 22 May 2021).

55. BEAMA Guide to Surge Protection Devices (SPDs): Selection, Application and Theory. Available online: https:/ www.beama. org.uk/asset/1FE338CE-4969-4B56-9637F3DEA6C683C6/ (accessed on 22 May 2021).

56. Hossain, M.A.; Ahmed, M.R. Analysis of indirect lightning phenomena on solar power system. Int. J. Electr. Eng. 2014, 21, 127-133. 